\title{
Mapping a Conformational Epitope of Hemagglutinin A Using Native MS and Ultraviolet Photodissociation
}

M. Rachel Mehaffey ${ }^{1}$, Jiwon Lee ${ }^{2,3}$, Jiwon Jung ${ }^{4}$, Michael B. Lanzillotti ${ }^{1}$, Edwin E. Escobar ${ }^{1}$, Keith R. Morgenstern ${ }^{1}$, George Georgiou ${ }^{3,4,5,6,7}$, and Jennifer S. Brodbelt ${ }^{1 *}$

${ }^{1}$ Department of Chemistry, ${ }^{3}$ Department of Chemical Engineering, ${ }^{4}$ Department of Biomedical Engineering, ${ }^{5}$ Institute for Cellular and Molecular Biology, ${ }^{6}$ Center for Systems and Synthetic Biology, and ${ }^{7}$ Department of Molecular Biosciences, University of Texas at Austin, Austin, TX 78712

${ }^{2}$ Thayer School of Engineering, Dartmouth College, Hanover, NH 03755

Corresponding author:

Jennifer S. Brodbelt

University of Texas at Austin

Department of Chemistry

Austin, TX 78712-0165

jbrodbelt@cm.utexas.edu

Phone: (512)-471-0028

\section{Supporting Information:}

Experimental. Detailed descriptions of the protein expression and purification, and on-line sizeexclusion chromatography experiment.

Figure S1. Expressed protein sequences of the antibody and antigen.

Figure S2. Crystal structure of HA1 bound to the Fab fragment of an IgG antibody.

Figure S3. MS/MS spectra and sequence coverage maps of the antigen.

Figure S4. ESI-MS and MS/MS spectra of the antibody.

Figure S5. Sequence coverage maps of the antibody.

Figure S6. ESI-MS for optimization of the in-source trapping voltage.

Figure S7. ESI-MS and MS/MS spectra of the antibody-antigen complex.

Figure S8. Sequence coverage maps for each component of the antibody-antigen complex.

Figure S9. Comparison of sequence coverage of the antigen before and after complexation with the antibody.

Figure S10. Sequence ion type distributions for the four distinct regions of the antigen.

Figure S11. Number of sequence ions produced adjacent to each residue.

Figure S12. Distributions of ion types produced adjacent to each residue.

Table S1. Identified fragment ions from MS/MS spectra of the antigen.

Table S2. Identified fragment ions from MS/MS spectra of the antibody.

Table S3. Identified fragment ions from MS/MS spectra of the antibody-antigen complex. 


\section{EXPERIMENTAL}

Recombinant Protein Expression \& Purification

Genes for the antibody and antigen involved in the study were purchased as gBlocks (Integrated DNA Technologies) and cloned into the pcDNA3.4 vector (Invitrogen). For monoclonal antibody expression, heavy and light chain plasmids for D1 H1-17/H3-14 IgG were transfected into Expi293 cells (Invitrogen) at a 1:3 ratio. After incubating for 5 days at $37^{\circ} \mathrm{C}$ with $8 \% \mathrm{CO}_{2}$, the supernatant containing secreted antibodies was collected by centrifugation at $500 \times \mathrm{g}$ for $15 \mathrm{~min}$ at room temperature. Supernatant was passed over a column with $1 \mathrm{~mL}$ Protein A agarose resin (Thermo Scientific) three times to ensure efficient capture. After washing the column with $20 \mathrm{cv}$ of PBS, antibodies were eluted with $3 \mathrm{~mL}$ of $100 \mathrm{mM}$ glycine-HCl, pH 2.7 and immediately neutralized with $1 \mathrm{~mL}$ of $1 \mathrm{M}$ Tris-HCl, $\mathrm{pH}$ 8.0. Antibodies were buffer-exchanged into PBS utilizing Amicon Ultra-30 centrifugal spin columns (Millipore). Similarly, for the HA1 antigen expression, after incubating for 5 days at $37{ }^{\circ} \mathrm{C}$ with $8 \% \mathrm{CO}_{2}$, the supernatant containing secreted protein was collected by centrifugation at $500 \times \mathrm{g}$ for $15 \mathrm{~min}$ at room temperature. Supernatant was passed over $2 \mathrm{~mL}$ Ni-NTA agarose (QIAGEN) affinity column in gravity mode. Flow-through sample was collected and passed through the column three times. The column was washed with $15 \mathrm{cv}$ of 10 $\mathrm{mM}$ imidazole, $150 \mathrm{nM} \mathrm{NaCl}, 100 \mathrm{mM}$ Tris- $\mathrm{HCl}, \mathrm{pH} 7.5$ prior to eluting with $5 \mathrm{cv}$ of $250 \mathrm{mM}$ imidazole, $150 \mathrm{nM} \mathrm{NaCl}, 100 \mathrm{mM}$ Tris-HCl, $\mathrm{pH}$ 7.5. Eluates were then buffer-exchanged into PBS using Amicon Ultra-30 centrifugal spin columns (Millipore).

\section{Size-Exclusion Chromatography}

The on-line size-exclusion chromatography experiments were performed using a Dionex LC system (Thermo Scientific) interfaced to the modified Q Exactive UHMR mass spectrometer. Separation was carried out on a $2.1 \mathrm{~mm} \times 150 \mathrm{~mm}$ Waters ACQUITY UPLC Protein BEH SEC column with a $200 \AA$ pore size and $1.7 \mu \mathrm{m}$ particle size (Milford, MA). An isocratic mobile phase comprised of $20 \mathrm{mM}$ ammonium acetate $\left(\mathrm{pH}\right.$ 6.8) and flowing at $100 \mu \mathrm{L} \mathrm{min}{ }^{-1}$ was used to elute a $5 \mu \mathrm{L}$ injection of the 1:2 antibody:antigen sample $(1 \mu \mathrm{g} / \mu \mathrm{L})$ after deglycosylation. An applied voltage of $4 \mathrm{kV}$ on the HESI source interfacing the LC to the MS was used to ionize the effluent. An in-source trapping value of $-150 \mathrm{~V}$ allowed efficient desolvation of the antibody-antigen complex. ESI-MS were collected at a resolving power of 12500 at $\mathrm{m} / \mathrm{z} 200$. 
Figure S1. Expressed sequences of the (A) D1 H1-17/H3-14 IgG monoclonal antibody and (B) HA1 domain (residues 57-267) of the corresponding HA protomer from H1N1 A/California/04/2009 used for all experiments. Cysteine residues are shown in yellow font, and expected disulfide linkages are represented as dotted lines. Calculated average masses for each sequence account for disulfide bonds. A G0F glycan is expected to exist at N306 on the heavy chain of the antibody (highlighted in blue).

\section{(A) D1 H1-17/H3-14 IgG monoclonal antibody (145,650 Da)}

\section{Heavy chain $(49,713 \mathrm{Da})$}

N QVQLQESGPGLVKPSESLSLTCSVSGGSVSSNLHYWSWIRQLPGKGLEWI 50

51 GYISYTGSTKYNPSLNGRVTLSIDASKNQFSLELSSVTAADTAVYYCARD 100

101 FFEKLIADDLNAFDIWGQGTMVTVSSASTKGPSVFPLAPSSKSTSGGTAA 150

151 LGCLVKDYFPEPVTVLWNSGALTSGVHTFPAVLQSSGLYSLSSVVTVPSS 200

201 SLGTQTYICNVNHKPSNTEVDKKVEPKS ĊKTHTCPPCPAPELLGGPSVF 250

251 LFPPKPKDTLMISRTPEVTC̣VVDVSHEDPEVKFNWYVDGVEVHNAKTKP 300

301 REEQYNSTYRVVSVLTVLHQDWLNGKEYKCKVSNKALPAPIEKTISKAKG 350

351 QPREPQVYTLPPSRDELTKNQVSLTCְLVKGFYPSDIAVEWESNGQPENNY 400

401 KTTPPVLDSDGSFFLYKLTVDKSRWQQGNVFSCSVMHEALHNHYTQKSLS 450

451 LSPGK C

\section{Light chain $(23,112 \mathrm{Da})$}

N DIRVTQSPSSLSASVGDRVTITCCRASQSISRSLNWYQQRPGKAPKFLIYA 50

51 ASNLQSGVPSRSGGGSGTDFTLTISSLQPEDFATYYCQTYSRTFGQGT 100

101 KADIKRTAAAPSVFIFPPSDEQLKSGTASVVCLLNNFYPREAKVQWKVDN 150

151 ALQSGNSQESVTEQDSKDSTYSLSSTLTLSKADYEKHKVYACEVTHQGLS 200 201 SPVTKSFNRGE

(B) HA1 domain (residues 57-267) from H1N1 A/California/04/2009 (25,402 Da)
N APLHLGKCNIAGWILGNPECESLSTASSWSYIVETPSSDNGTCYPGDFID 50
51 YEELREQLSSVSSFERFEIFPKTSSWPNHDSNKGVTAACPHAGAKSFYKN 100
101 LIWLVKKGNSYPKLSKSYINDKGKEVLVLWGIHHPSTSADQQSLYQNADT 150
151 YVFVGSSRYSKKFKPEIAIRPKVRDQEGRMNYYWTLVEPGDKITFEATGN 200
201 LVVPRYAFAMERNAGSGHHHНHНHН 
Figure S2. Crystal structure with a $180^{\circ}$ view of the HA1 domain of an HA protomer (H3N2 $\mathrm{A} /$ Texas/50/2012) bound to the antigen binding fragment (Fab) region of the S5V2-29 IgG monoclonal antibody (PDB ID: 6E4X) with subunits labelled. The two epitope regions are highlighted (red, green) along the HA1 subunit (gray) with the corresponding epitope sequences from the HA strain expressed for this study shown (numbering is based on the HA protomer sequence; these residues correspond to T35-R55 and F163-Y193 in the expressed HA1 sequence shown in Figure S1B). The heavy chain (HC) and light chain (LC) of the antibody are colored separately (turquoise and orange, respectively).

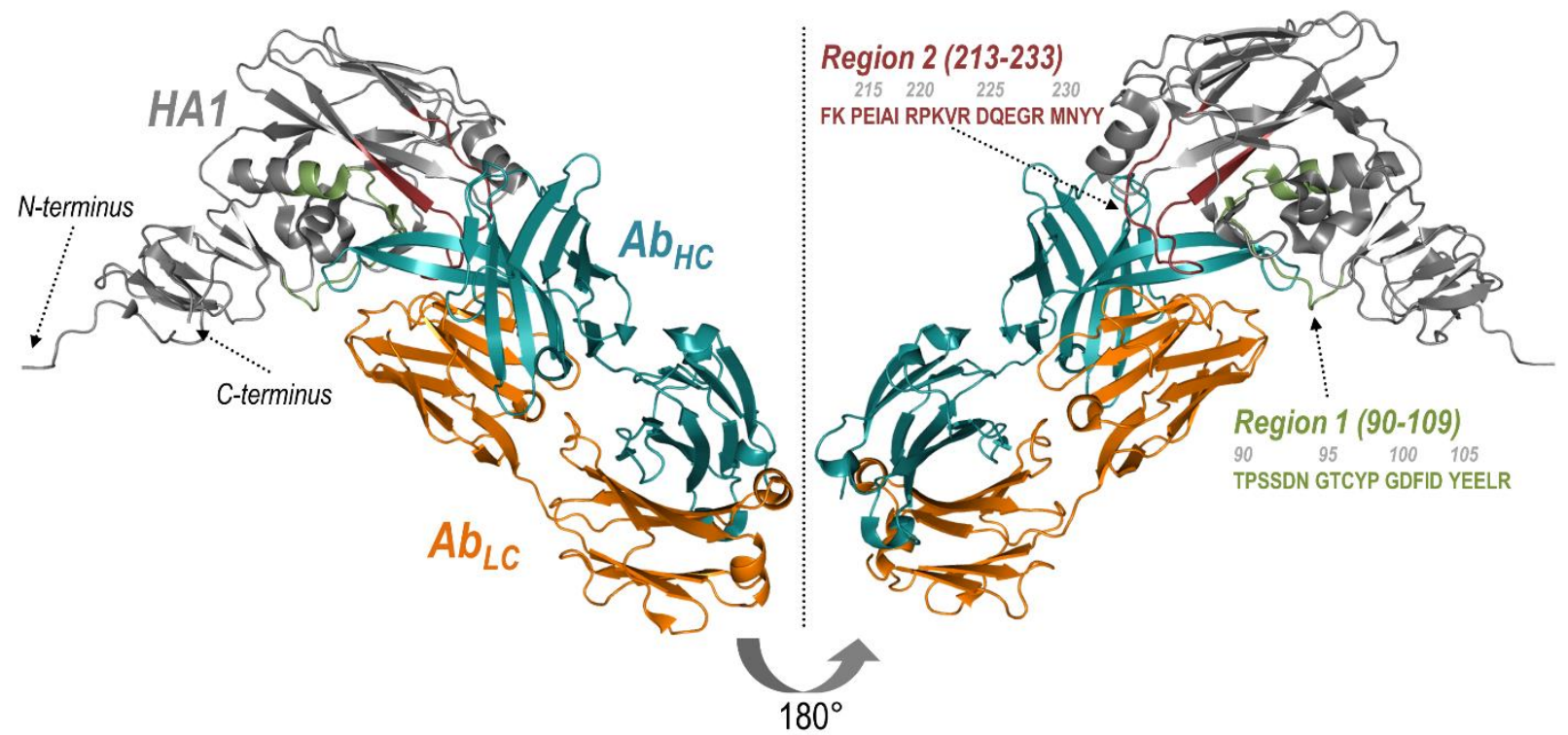


Figure S3. (A) MS/MS spectra resulting from activation of the 10+ charge state of HA1 with HCD (left) and UVPD (right). Several abundant fragment ions are identified and labelled. (B) Corresponding deconvoluted MS/MS spectra in which the precursor is denoted with a filled circle. Monoisotopic masses identified as assignable fragment ions originating from backbone cleavages of HA1 are used to create the sequence coverage maps in (C). Searches accounted for disulfide bonds at all four cysteine residues (highlighted in gray). Lists of all matched fragment ions are given in Table $\mathbf{S 1}$.

(A)
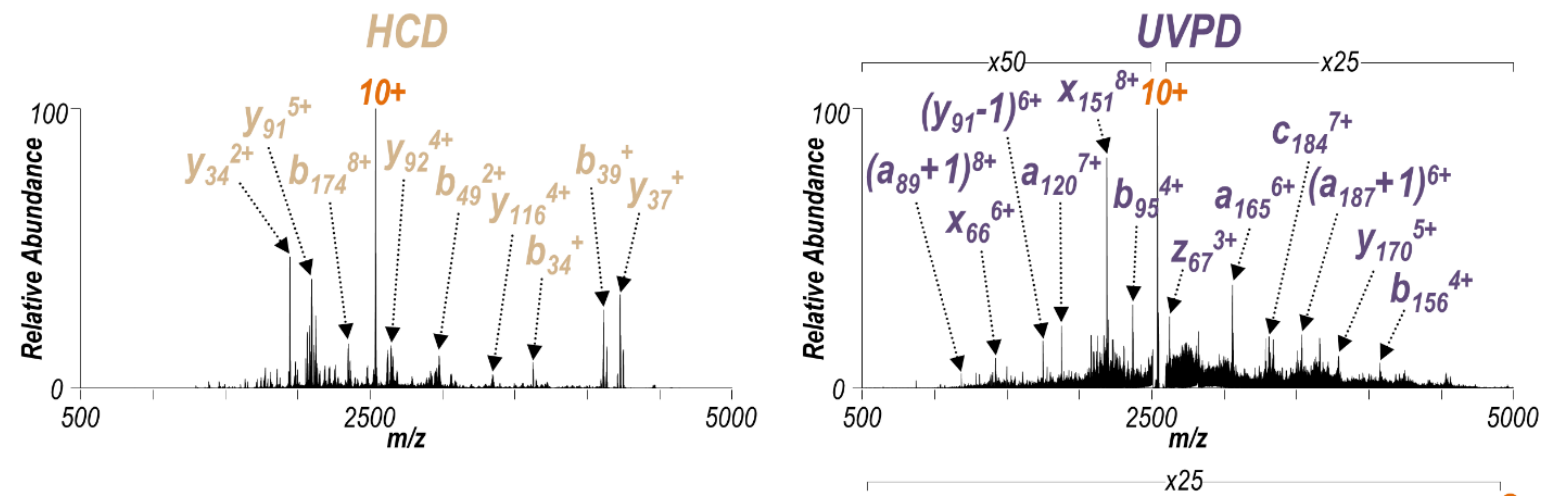

(B)
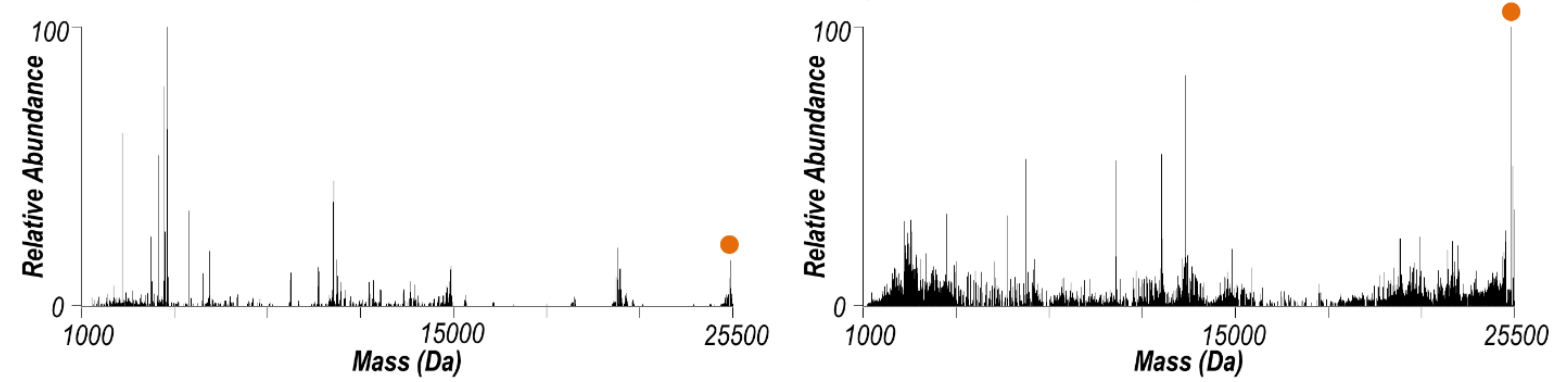

A P L H L G K C N I A G W I L G N P E C E\S\LIS T A S S W S Y IIVIE\T PIS S DIN G T C Y P G D F I D 1 Y E E LRE Q L S S V S SFERFE I F P K T S S

(C)

101 L I W L V KLK G NLS YLP KLLLS KLS Y I LNLDLKЦG K E

126 V LLVLLLWLG ILHLHLP SLTLS A DLQLQLSLLLY QLN A DLT

151 Y V F V G S S R Y S K K F K P ELI A ILR P K V RlD QLELG RLM NLY Y WLT LLV ELP G DLK ILTLFLELALT G N

201 LLVLVLP R YLA FLALM ELR NLA G S G H H H H Н Н Н Н

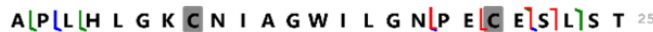

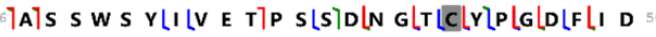
YLE LE LLLRLE]QLL】S S V S S F E RLFLE I F P K T S S S

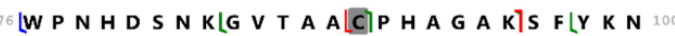

$c / z$

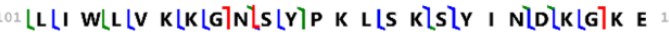

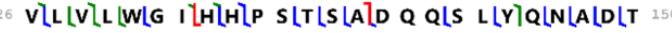

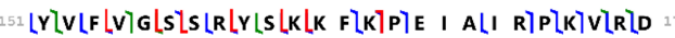

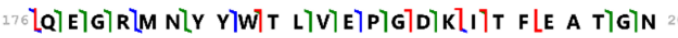

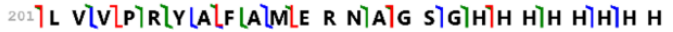


Figure S4. (A) ESI-MS of the D1 H1-17/H3-14 antibody in $20 \mathrm{mM}$ ammonium acetate after reaction with PNGase F. Observed charge states are labelled and glycoforms are denoted with turquoise colored circles. Even with the short reaction time, the most abundant species corresponds to removal of the G0F glycan from both heavy chains. The $25+$ charge state of the antibody without glycans was selectively isolated and activated with (B) HCD and (C) UVPD. Several abundant fragment ions resulting from HCD (tan) and UVPD (purple) are labelled corresponding to the sequences of the light chain (light color) or heavy chain (dark color).
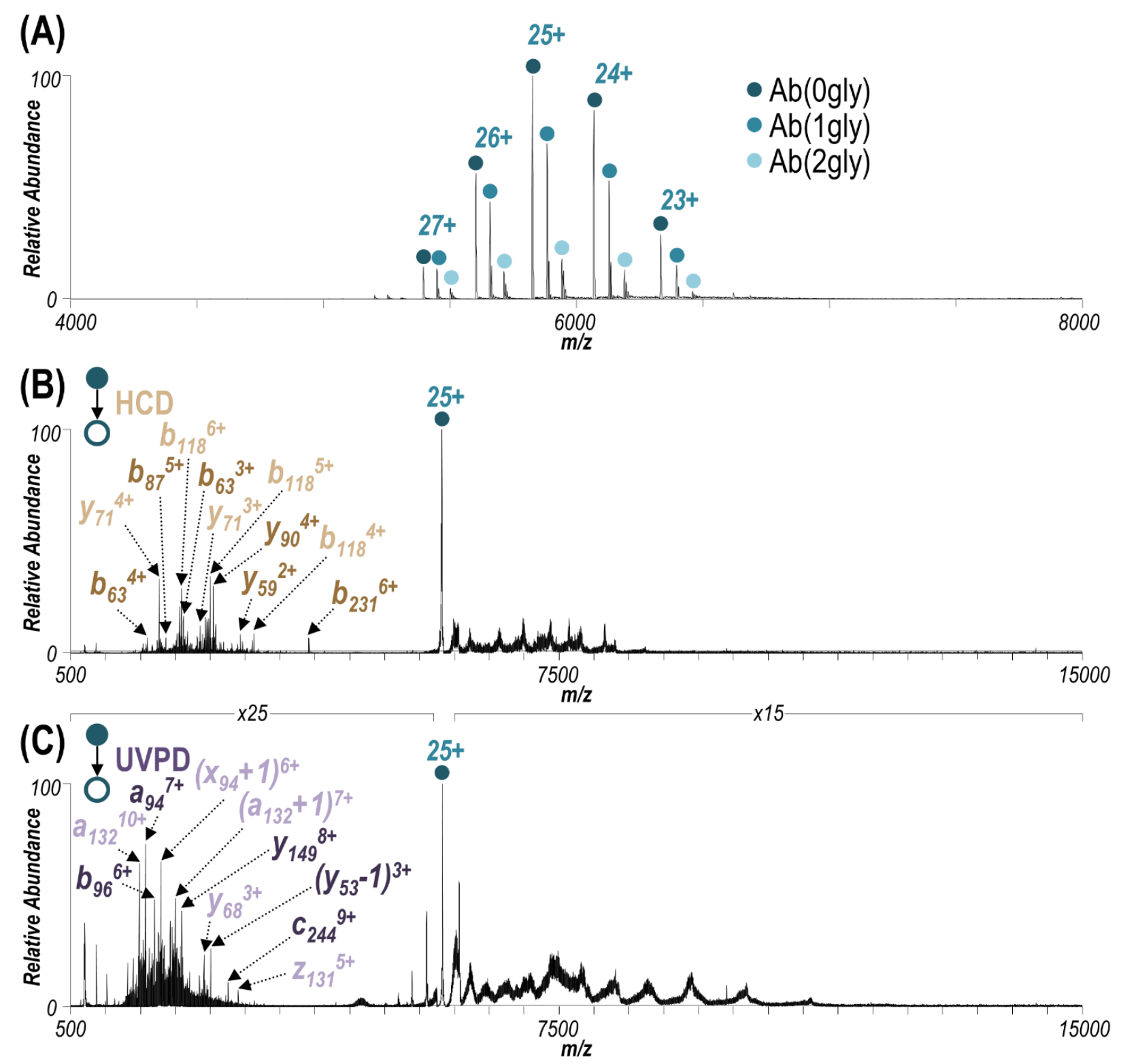
Figure S5. (A) Spectra resulting from deconvolution of the HCD and UVPD MS/MS spectra of the D1 H1-17/H3-14 antibody shown in Figure S4. Monoisotopic masses identified as assignable fragment ions originating from backbone cleavages of the (B) light chain and (C) heavy chain of the antibody are used to create the sequence coverage maps. The eight disulfide bonds that stabilize the antibody structure (highlighted in gray) were assumed to be intact for fragment ion identification. Table $\mathbf{S 2}$ gives a list of all matched fragment ions.

(A)
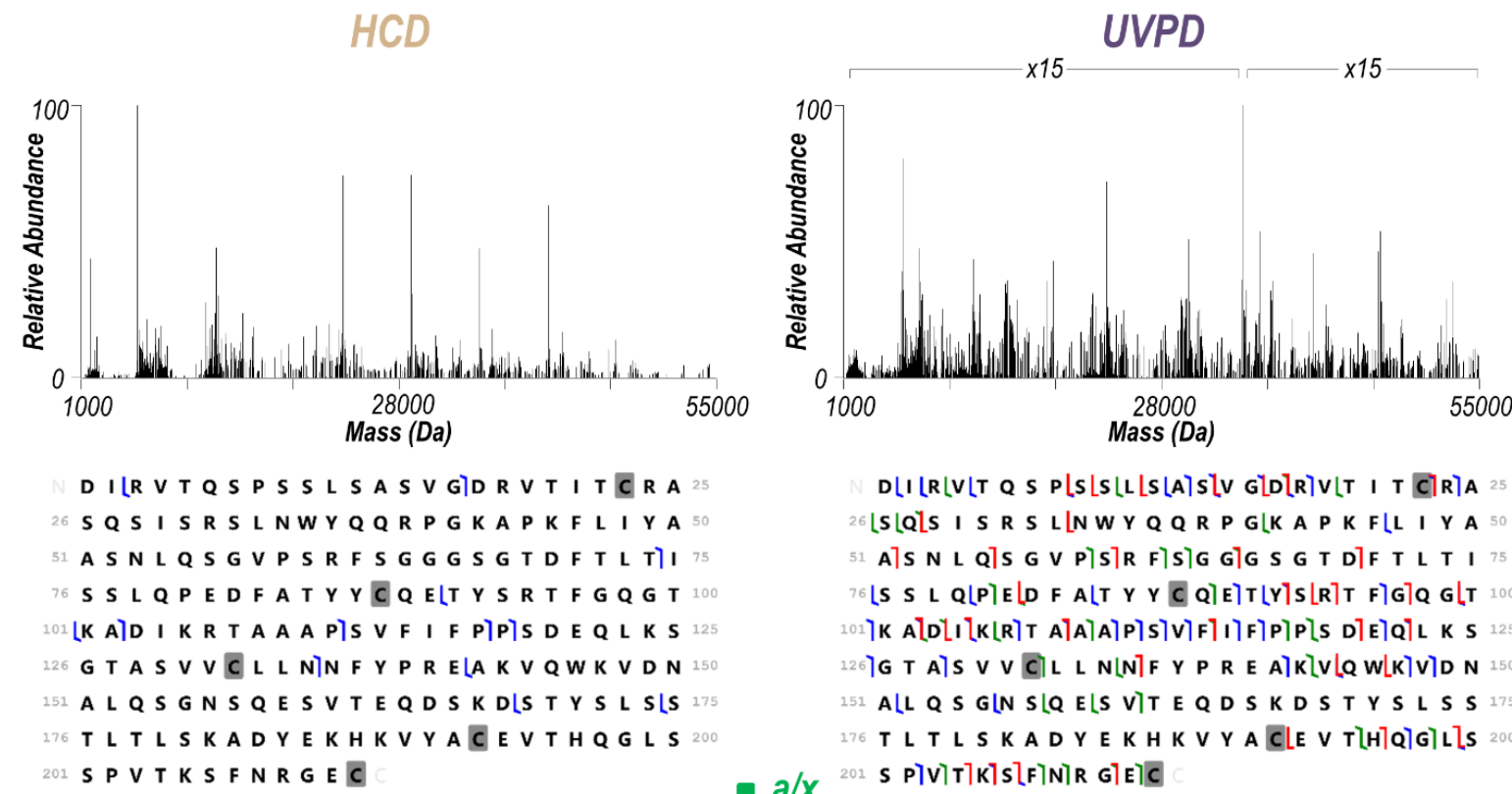

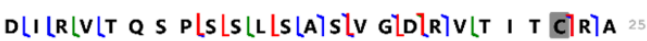
[LSLQLS I S R S LLN W Y Q Q R P GLK A P K FLL I Y A 50

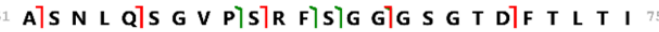
${ }^{16}$ LS S L Q Q P)

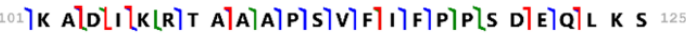

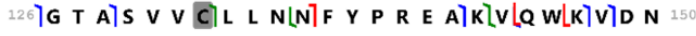
151 ALL Q S GLN S Q ELS V\T E QD S K D S T Y S L S S 175

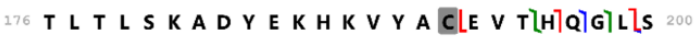

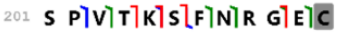

\section{$45 \%$ sequence coverage}

Q V Q L Q E S GLP G LLV KLP S E LS L S LL TT CLS V S 25 †G G S VLSLS NLL H Y W S W I R Q LךP G K G LךE WW I

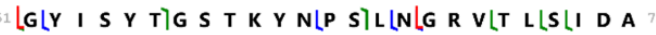
${ }^{6}$ S K N Q F S L ELLLS LS V TLA\A D TT A)V Y Y YC A R\D 100

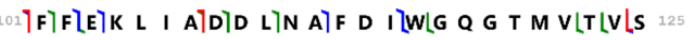

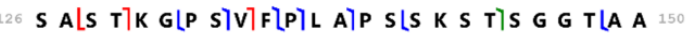
251 L GLC L V K D Y F P E PLV T V L W NLS G A L T SLG 173 ${ }^{176}\lfloor$ L $\lfloor$ H LT TLF P A V L Q S S G LLY S L LS S V V T V P S S 200

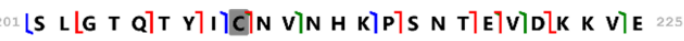

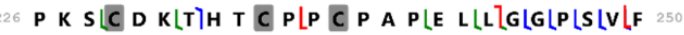
$251 \mathbf{L}\lfloor\mathbf{F}\lfloor\mathbf{P}\lfloor\mathbf{P}\lfloor\mathbf{K}\lfloor\mathbf{P}$ K $\lfloor\mathbf{D}\lfloor T\lfloor\mathbf{L} \mathbf{M}\lfloor\mathbf{I}\lfloor\mathbf{S}\lfloor\mathbf{R}\lfloor T\lfloor\mathbf{P}$ E V $\rceil \mathbf{T}\lfloor\mathbf{C}$ V V V D V 275

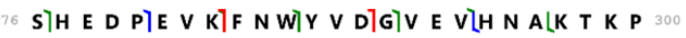

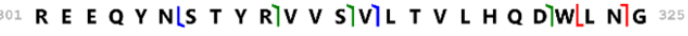

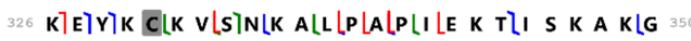
351 Q)P R E PLQ V Y T L P P P\S R D E L T K N Q V S LlT 375

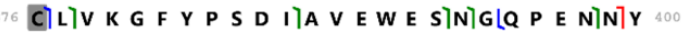
${ }_{401}$ LK TLT P P V L D S D G S F FLLLY K LLT V D K S R W 425

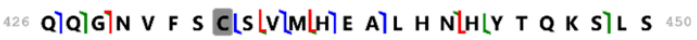
451 L S P G]K $37 \%$ sequence coverage 
Figure S6. ESI-MS of the antibody-antigen complex collected using various in-source trapping energies $(-10 \mathrm{~V}$ to $-250 \mathrm{~V})$ to determine the ideal value for analysis. Up to three species are observed including HA1 monomer (orange), 1:2 antibody:antigen complex (turquoise), and 1:1 antibody:antigen complex (green). At low IST values (top), the complex is poorly desolvated resulting in many adducts, while at high IST values (bottom) significant disruption of the complex and ejection of one HA monomer occurs.

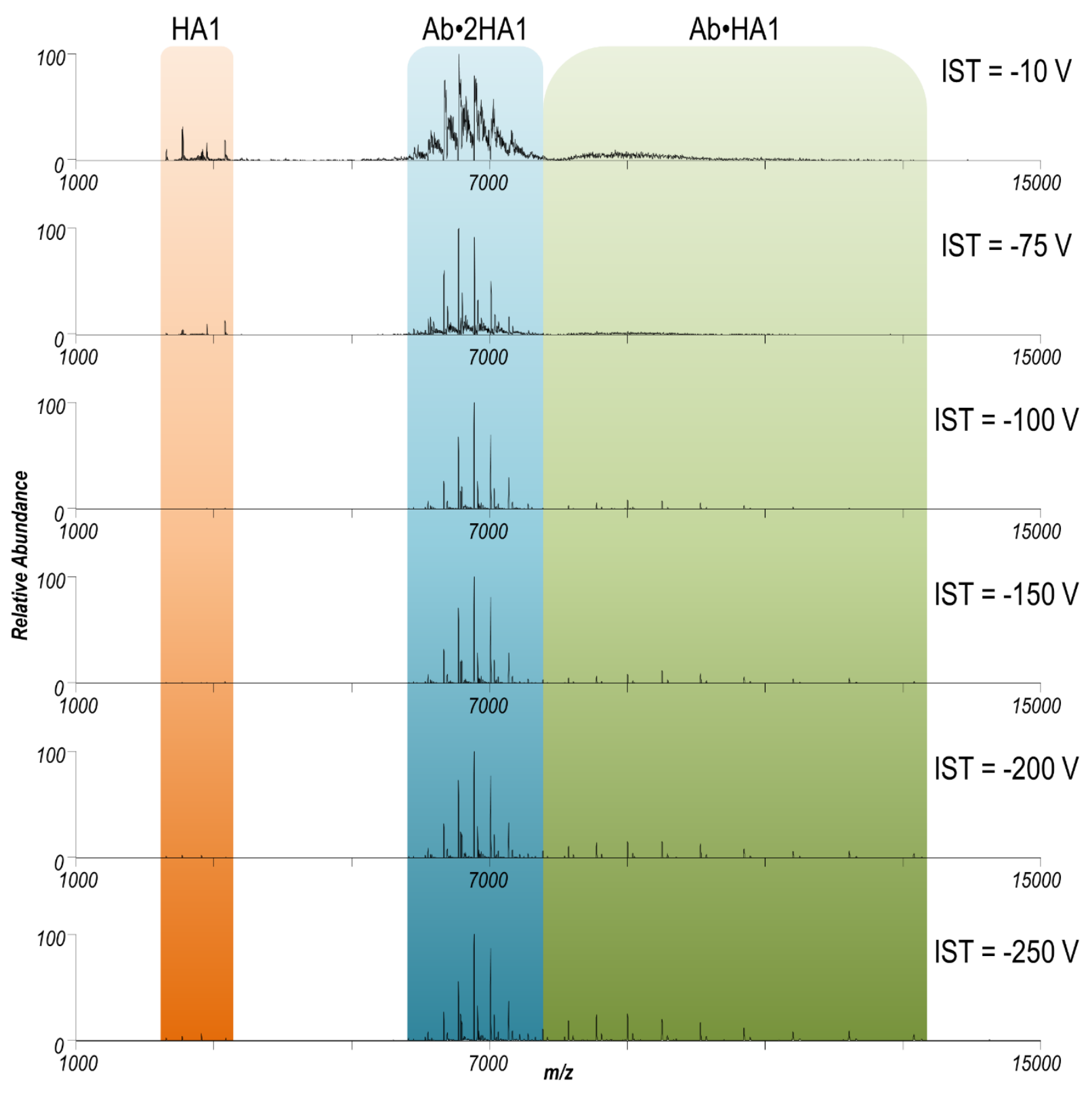


Figure S7. (A) ESI mass spectrum of a solution containing 1:2 antibody:antigen using an in-source trapping energy of $-100 \mathrm{~V}$. Charge states of the two observed species are labelled: Ab•2HA1 (turquoise) and Ab•HAl (green). The 29+ charge state of the antibody-antigen complex was selectively isolated and activated with (B) HCD or (C) UVPD to yield the MS/MS spectra. Observed charge states of intact subunits of HA1 (orange) or Ab•HAl (green) are identified, suggesting antigen ejection was a more favored fragmentation pathway for HCD compared to UVPD.

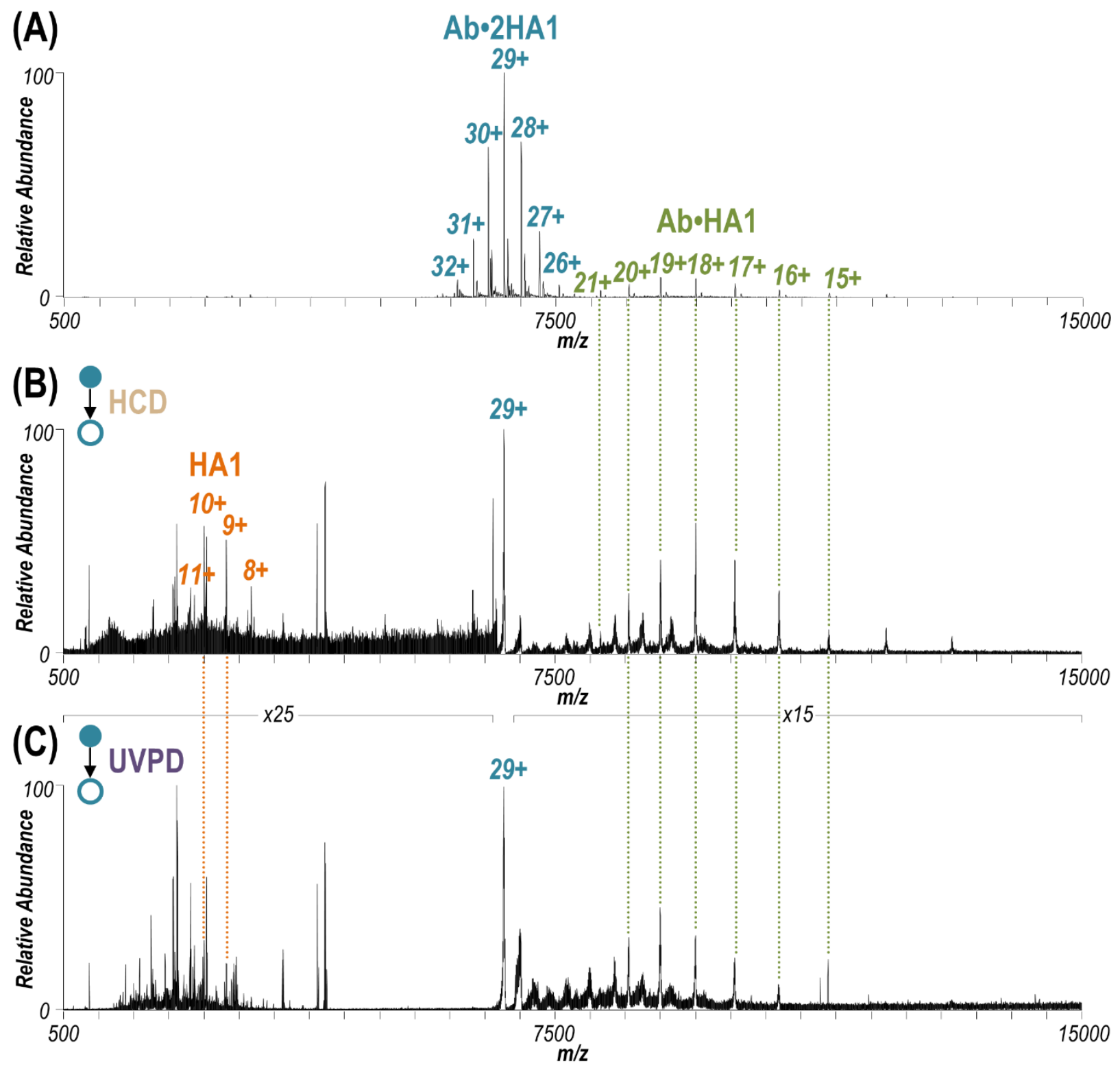


Figure S8. (A) Deconvoluted HCD (left) and UVPD (right) mass spectra corresponding to the MS/MS spectra of the antibody-antigen complex in Figure S7. Fragment ions originating from backbone cleavages were searched against the sequences of (B) HA1, (C) antibody light chain, and (D) antibody heavy chain to create the sequence coverage maps. All cysteine residues (highlighted in gray) were assumed to be disulfide bound. None of the observed fragment ions matched expected backbone cleavages for more than one of the three sequences. Sequence coverages are reported for each protein in the complex. A list of all identified fragment ions is given in Table S3.

(A)

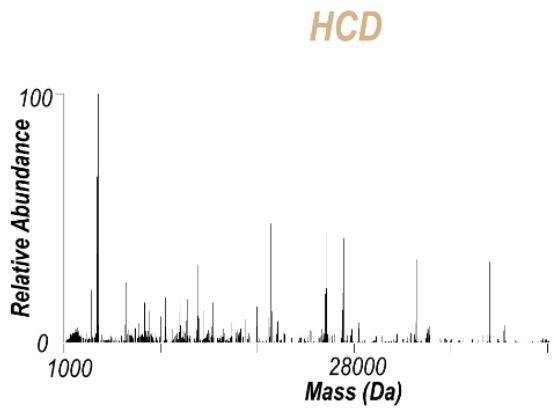

A P L H L G K C N I A GW I L G N P E C E\S\LIS\T A S S W S Y I IV EITTPS D DINLG T C Y P G D F I D YEELREQLSS VSSFERFEIFPKTS S

(B) WPNHDSNKG VTAACPHAGAKSFYK N 101 L I W L V K K G]NLS Y P K L S K S YLI N DLK G K E

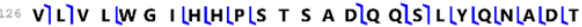
51 Y V F V GS SR Y S K K F KLPE I A I R P K V R D 76 LQ ELG]R M N Y Y W TLL VLE\P G DLKLILT F ELA TLG N 201 L V V P R Y A F A M ELR NLA G S G H H H H H H H H $20 \%$ sequence coverage

(C) S QS I SIRS LNWYQQRPGKAPKFL I YA A S N L QLS G V PSRF S G G GS GTDFT L T I S S L Q P E D]F A T YLY C\Q E T Y S R T FLGLQ GLT 101 K A DLI K R T A A A PlS V\F\I F P P S DE Q L K S ${ }_{26}$ G T A S V V C L L N N F Y P R E A K V Q WLK V D N ALQS GNS QES VTEQDS KDSTYSLS S T L T L S K A D YEKHKV YACE V TH Q GLLS S P V T K S F NRGE C $9 \%$ sequence coverage

Q V Q L QE S G P GLL V K P S E S L S L TTC S V S G G S V S S N L H Y W S I R Q LPG]KG LEW I G Y I S Y T GSTKYNPS LNGR VTLS I DA S K N QFS LELS S V TAADTAVYY CAR D 100 F F E K L I A D D L N A]F D I W G Q G TLM V T V S 12 S A S T K G P S V F P LLAPS S K S T S G G T A A 150 L G C L V K D Y F P E P V T V LLWN S G A L T S G 17 V H T F P A VL QS S GLYSLS S V V T V P S S 200 S L G T Q T Y I C N V NLHLK P S N T E V D K K V E 22

(D) 26 P K S C D K T H T C P P C P|A]P E L L G]G P S V F 250 251 L F P P K P K D T L M I S R T P E V T C V V V D V 27 SHEDPEV K F NWY VDG VEVHINAKTK P 3 R E E Q Y N S T Y R V V S LV LIT V L H Q D W]L N G K E Y K C K V S NLK A L P A P I E K T I S KLA K G 350 QLP R E P QLV Y T LP P S R DE LLT K N Q V S L T C L V K G F Y PS D I A VEWE S N G QPELN N Y K T T P P V L D S D G S F F L Y K L T V D K S R W Q Q G N V F S C S VLM HE A LLHLN H Y T Q K S L S L S P G K

$6 \%$ sequence coverage

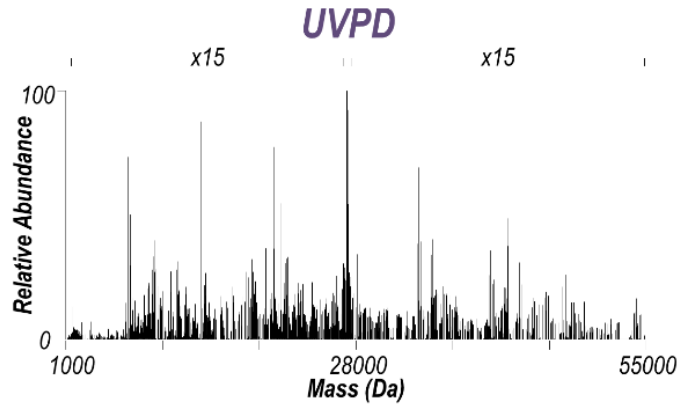

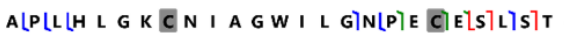
${ }_{6}^{6}$ A S SLW SLY ILV E T P S S D N G T C YLP GLD F I D 51 Y E E L RLE Q L S S V S S F ELRlF E I F P K T S S

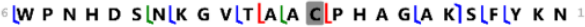

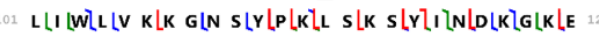

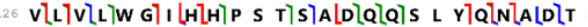
.51 YY $\lfloor V\lfloor F\lfloor V \backslash G \backslash S\lfloor S \backslash R\lfloor Y\lfloor S\lfloor K\lfloor K$ F K P E I A I R P K V R R D

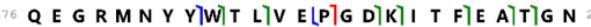

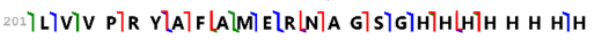
$49 \%$ sequence coverage

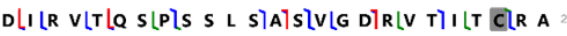
SLQ $S\lfloor I$ S RLSLL NLW YLQ Q)R P G K A P K F LLI]Y A

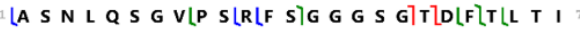

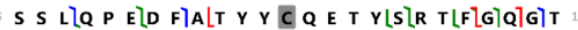

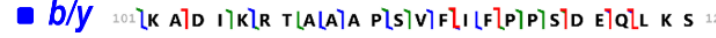
- $c / Z$

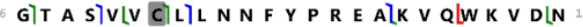
LA LTQ S GIN S Q QE S VLT E QDS K D S T Y S LIS S

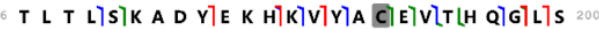

$2017 S$ P\V\T K\S F\N RTG ETC

\section{$46 \%$ sequence coverage}

Q VLQ L Q E SLG P G L V K P SLE]SLL S LLT C SLV S ${ }^{6}$ G G S V S S N L H Y WLS W I R Q L P G KLGLLLEW I L LG Y I S Y T G S T K YLN P]S L]N G R VV TLL SLI ID A S K N Q F]S LLE\LLS S VLT ALA D T A V Y YLC A]R]D

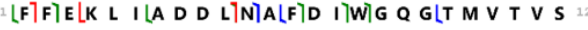
126 SLALS TLK G P SLV FlP L ALP S S KLS T S G GLTlALA LL G C L VLK DLY F P E P V]T V LLWN S G A L T S G

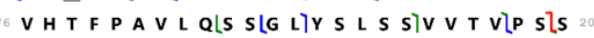

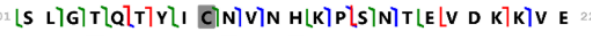

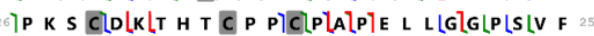

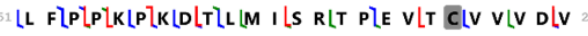
[S H E D P E V\K F N W Y V DlG V]E V H N A K T K P

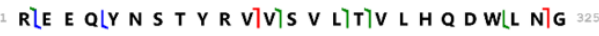

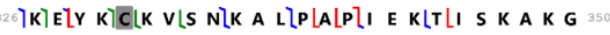
Q PLRLELP Q]V YLTLL PLP S RLD E LLTLK N Q V S L T 375 ${ }^{6}$ C $\mid L$ VLK G]F YLP SLD I]A]V E W E S N G Q P E N N Y 400 K T T P)P\V L D S D G S F \F L Y K L T V D K]S R W 6 Q Q G N V F S ClS $\lfloor$ V\MLH ${ }^{151} 7$ LIS P G K

$37 \%$ sequence coverage 
Figure S9. Comparison of the sequence coverage of HA1 afforded by HCD (left) and UVPD (right) for activation of (A) unbound HA1 and the (B) 1:2 antibody:antigen complex. Corresponding MS/MS spectra are shown in Figure S3 for unbound HA1 (10+) and Figure S7 for the complex (29+). Sequence coverages are reported below each map with the complex yielding lower sequence coverage than the unbound hemagglutinin A for both HCD and UVPD. The two epitope regions are highlighted: epitope region 1 (green) and epitope region 2 (red).

(A)

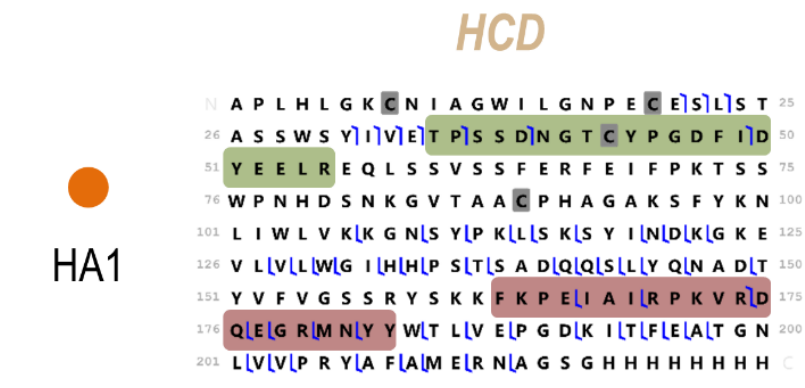

B)

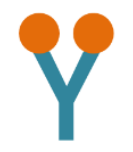

APLHLGKCN I AGWI LGNPECE]S]LIS]T

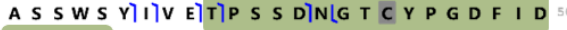

YEELREQLS S VSSFERFE I F P K T S S

WPNHDSNKG V TA C PHAGAKSFYK N

101 L I W L V K K G]NLS Y P K L S K S YLI N DLK G K E 12

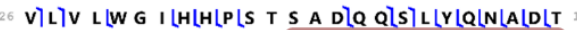

$\mathrm{Ab} \cdot 2 \mathrm{HA} 1$

Y VFVGSSRYSKKFKLPEIAIRPKVRD

LQ ELG]R MNYYWTLLVLE\P G DLKLILT F ELA TLG N

21 L V PRYAFAMELR NLA G S GHHHHHHH

$20 \%$ sequence coverage 
Figure S10. Bar graphs of the distribution of fragment ion types across several different regions of HA1 for (A) HCD and (B) UVPD showing pairs of stacked bars representing unbound HA1 (left bar) and the Ab-2HA1 complex (right bar), corresponding to the sequence coverages shown in Figure 3 for the entire protein, epitope region 1, epitope region 2 and the rest of the protein. Residues 35-55 and 163-183 of the expressed HA1 sequence encompass the two expected epitope regions (or residues 90-109 and 213-233 in the HA protomer sequence). The rest of the protein represents the entire sequence excluding those two regions.

\section{(A) HCD}

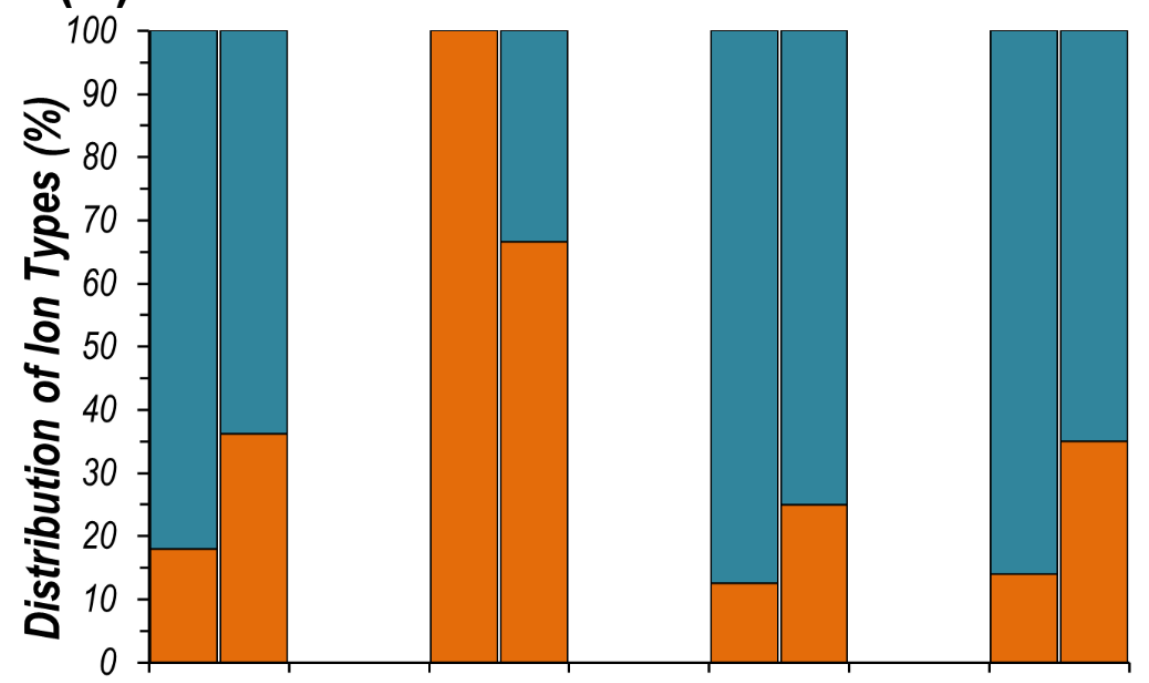

Entire Protein Epitope Region 1 Epitope Region 2 Rest of Protein

\section{(B) UVPD}

\section{Protein Region}

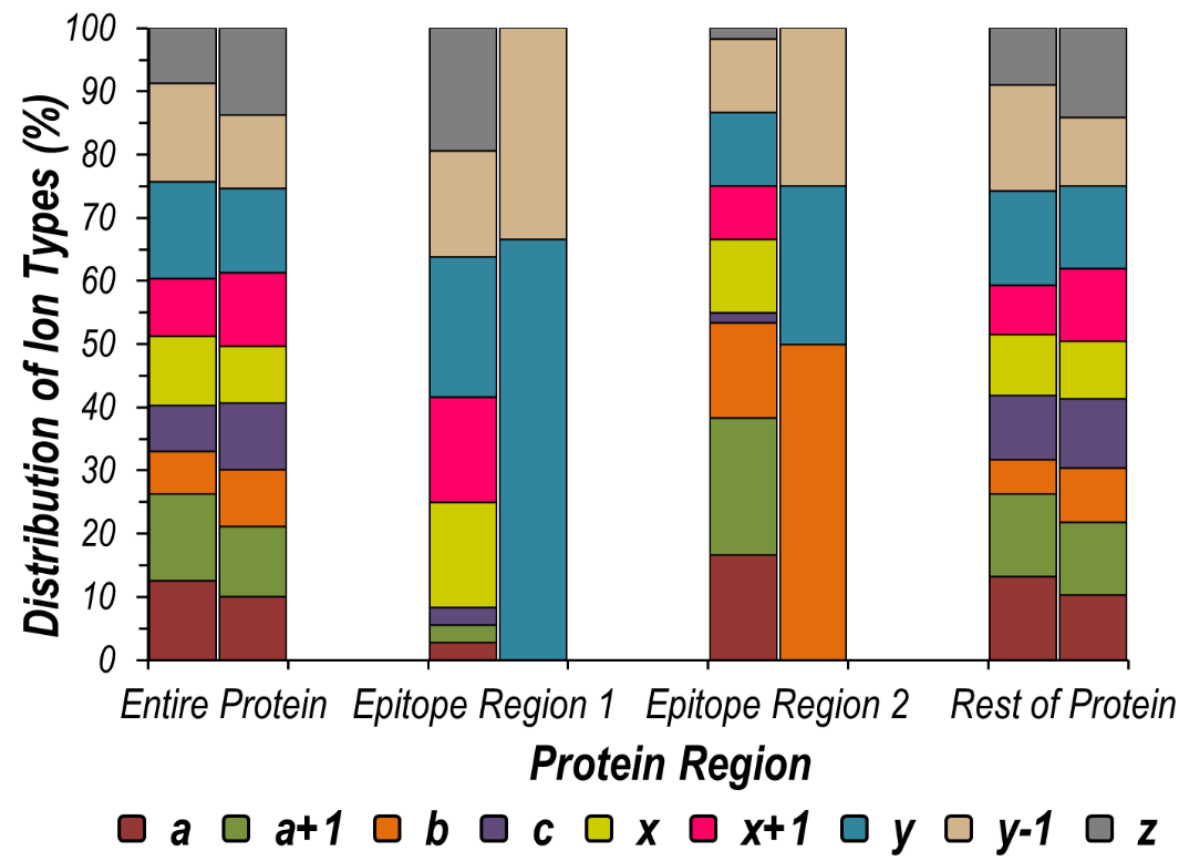


Figure S11. Plots of the number of HA1 sequence ions (originating from backbone cleavages along the protein sequence) as a percentage of the total number possible per residue resulting from activation of (1) unbound HA1 (10+) (orange) or (2) antibody-antigen Ab•2HA1 complex (29+) (turquoise) using (A) HCD and (B) UVPD. The two epitope regions (residues 90-109 and 213-233 in the HA protomer sequence, or 35-55 and 163-183 in the expressed sequence) are outlined with dashed lines. Subtraction of the corresponding values yielded the difference plots in Figure 4.

\section{(A) HCD}

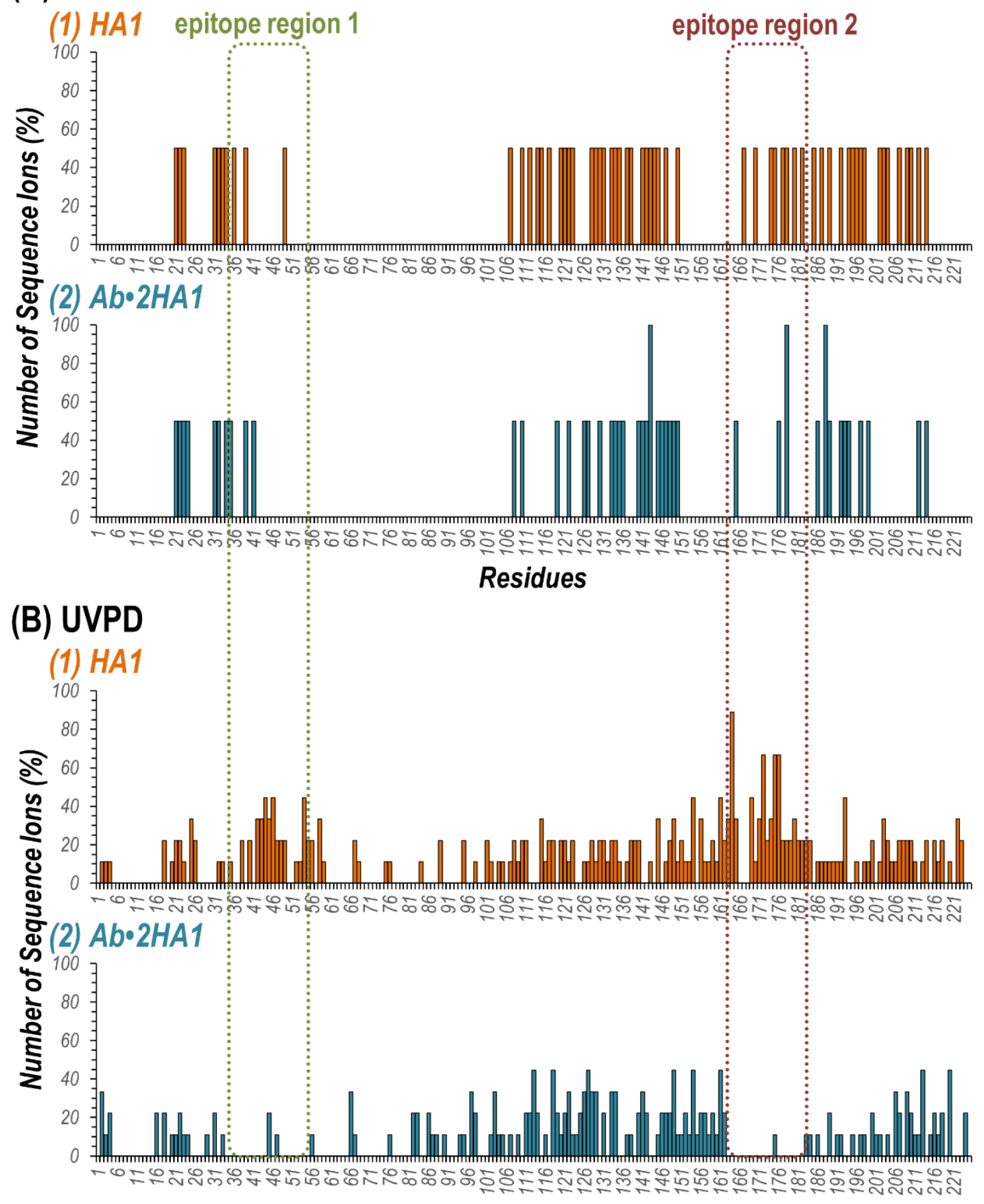

Residues 
Figure S12. Distribution of ion types corresponding to the plots in Figure S11 of the number of sequence ions originating from backbone cleavages at each residue for activation with (A) HCD and (B) UVPD of (1) unbound HA1 and (2) antibody-antigen complex. The dashed lines highlight the two epitope regions.

(A) HCD

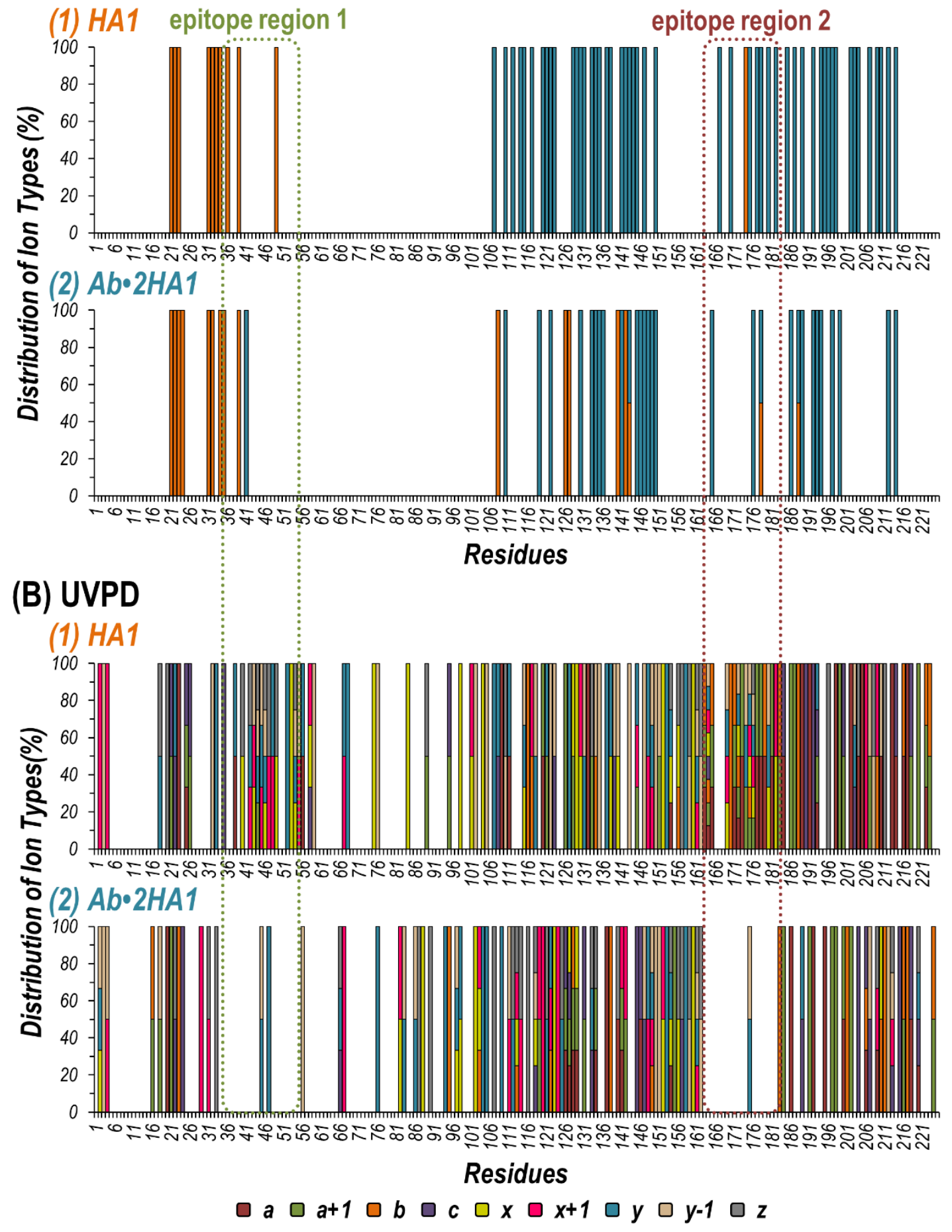


Table S1. Fragment ions identified as backbone cleavages produced upon activation of the 10+ charge state of unbound HA1 using (A) HCD and (B) UVPD. Identifications were made within \pm 10 ppm mass error.

(A) HCD of unbound HAI

\begin{tabular}{|c|c|c|c|}
\hline Identified Ion & Theoretical Mass & Observed Mass & Mass Error (ppm) \\
\hline b21 & 2214.071 & 2214.088 & 7.5 \\
\hline b22 & 2301.103 & 2301.120 & 7.3 \\
\hline b23 & 2414.208 & 2414.187 & -8.7 \\
\hline b31 & 3283.543 & 3283.573 & 9.0 \\
\hline b32 & 3396.657 & 3396.627 & -8.8 \\
\hline b33 & 3495.721 & 3495.695 & -7.4 \\
\hline b34 & 3624.738 & 3624.770 & 8.8 \\
\hline b36 & 3822.839 & 3822.864 & 6.7 \\
\hline b39 & 4111.963 & 4111.930 & -8.2 \\
\hline b49 & 5178.360 & 5178.319 & -7.8 \\
\hline b174 & 19437.666 & 19437.771 & 5.4 \\
\hline y12 & 1386.594 & 1386.608 & 9.8 \\
\hline y14 & 1656.738 & 1656.753 & 9.4 \\
\hline y16 & 1916.832 & 1916.821 & -5.9 \\
\hline y17 & 1987.875 & 1987.858 & -8.4 \\
\hline y19 & 2205.964 & 2205.981 & 7.9 \\
\hline y22 & 2622.181 & 2622.194 & 5.0 \\
\hline y23 & 2721.249 & 2721.276 & 9.8 \\
\hline y24 & 2820.345 & 2820.318 & -9.7 \\
\hline $\mathrm{y} 28$ & 3205.514 & 3205.538 & 7.7 \\
\hline y29 & 3276.551 & 3276.580 & 8.8 \\
\hline y30 & 3405.594 & 3405.619 & 7.4 \\
\hline $\mathrm{y} 31$ & 3552.688 & 3552.662 & -7.2 \\
\hline y32 & 3653.710 & 3653.740 & 8.2 \\
\hline y34 & 3894.889 & 3894.921 & 8.2 \\
\hline y37 & 4163.990 & 4164.023 & 8.1 \\
\hline y39 & 4392.141 & 4392.101 & -9.2 \\
\hline y41 & 4606.260 & 4606.233 & -6.0 \\
\hline $\mathrm{y} 44$ & 5118.466 & 5118.438 & -5.3 \\
\hline y46 & 5363.522 & 5363.528 & 1.1 \\
\hline$y 48$ & 5576.644 & 5576.681 & 6.5 \\
\hline
\end{tabular}




\begin{tabular}{|c|c|c|c|}
\hline $\mathrm{y} 49$ & 5705.687 & 5705.729 & 7.4 \\
\hline y51 & 5948.773 & 5948.815 & 7.2 \\
\hline y56 & 6585.191 & 6585.238 & 7.1 \\
\hline y59 & 6882.429 & 6882.396 & -4.8 \\
\hline y76 & 8886.443 & 8886.508 & 7.3 \\
\hline y79 & 9186.550 & 9186.619 & 7.5 \\
\hline y81 & 9477.672 & 9477.734 & 6.6 \\
\hline y82 & 9590.798 & 9590.756 & -4.4 \\
\hline $\mathrm{y} 83$ & 9677.788 & 9677.865 & 8.0 \\
\hline y84 & 9805.847 & 9805.921 & 7.6 \\
\hline $\mathrm{y} 85$ & 9933.995 & 9933.905 & -9.0 \\
\hline $\mathrm{y} 88$ & 10207.001 & 10207.088 & 8.5 \\
\hline y89 & 10308.049 & 10308.137 & 8.6 \\
\hline y91 & 10492.134 & 10492.230 & 9.0 \\
\hline y92 & 10629.193 & 10629.248 & 5.2 \\
\hline y93 & 10766.334 & 10766.252 & -7.6 \\
\hline $\mathrm{y} 95$ & 10936.437 & 10936.357 & -7.4 \\
\hline y96 & 11122.436 & 11122.428 & -0.7 \\
\hline y97 & 11235.520 & 11235.596 & 6.8 \\
\hline y98 & 11334.589 & 11334.661 & 6.3 \\
\hline y103 & 11860.900 & 11860.943 & 3.6 \\
\hline y104 & 11988.995 & 11989.088 & 7.8 \\
\hline y105 & 12104.073 & 12104.022 & -4.2 \\
\hline y106 & 12218.065 & 12218.112 & 3.9 \\
\hline y109 & 12581.245 & 12581.330 & 6.8 \\
\hline y111 & 12796.372 & 12796.476 & 8.1 \\
\hline y112 & 12909.456 & 12909.564 & 8.4 \\
\hline y114 & 13134.603 & 13134.560 & -3.3 \\
\hline y116 & 13384.766 & 13384.699 & -5.0 \\
\hline y119 & 13683.944 & 13683.858 & -6.3 \\
\hline
\end{tabular}

(B) UVPD of unbound HAI

\begin{tabular}{|c|c|c|c|}
\hline Identified Ion & Theoretical Mass & Observed Mass & Mass Error (ppm) \\
\hline$(\mathrm{a}+1) 21$ & 2187.084 & 2187.076 & -3.9 \\
\hline $\mathrm{c} 21$ & 2231.098 & 2231.110 & 5.7 \\
\hline $\mathrm{c} 22$ & 2318.130 & 2318.139 & 4.1 \\
\hline
\end{tabular}




\begin{tabular}{|c|c|c|c|}
\hline a23 & 2386.193 & 2386.206 & 5.6 \\
\hline$(a+1) 25$ & 2575.280 & 2575.270 & -4.0 \\
\hline a25 & 2574.272 & 2574.270 & -0.9 \\
\hline $\mathrm{c} 25$ & 2619.293 & 2619.297 & 1.3 \\
\hline $\mathrm{c} 26$ & 2690.331 & 2690.340 & 3.4 \\
\hline$(a+1) 26$ & 2646.317 & 2646.328 & 4.1 \\
\hline c35 & 3742.812 & 3742.815 & 0.8 \\
\hline $\mathrm{a} 38$ & 3968.908 & 3968.896 & -2.8 \\
\hline$(a+1) 44$ & 4622.119 & 4622.111 & -1.7 \\
\hline a56 & 6084.768 & 6084.770 & 0.3 \\
\hline c58 & 6370.932 & 6370.909 & -3.6 \\
\hline$(a+1) 89$ & 9722.494 & 9722.521 & 2.8 \\
\hline c95 & 10327.810 & 10327.853 & 4.1 \\
\hline$(a+1) 95$ & 10283.796 & 10283.842 & 4.4 \\
\hline c108 & 11904.723 & 11904.793 & 5.9 \\
\hline a109 & 11973.744 & 11973.812 & 5.7 \\
\hline a111 & 12223.840 & 12223.903 & 5.1 \\
\hline b116 & 12805.194 & 12805.189 & -0.4 \\
\hline b117 & 12892.226 & 12892.277 & 4.0 \\
\hline$(a+1) 120$ & 13255.429 & 13255.405 & -1.8 \\
\hline $\mathrm{a} 120$ & 13254.421 & 13254.421 & 0.0 \\
\hline$(a+1) 121$ & 13370.456 & 13370.535 & 6.0 \\
\hline c123 & 13599.586 & 13599.586 & 0.0 \\
\hline$(a+1) 126$ & 13911.778 & 13911.817 & 2.8 \\
\hline$(a+1) 128$ & 14123.931 & 14123.984 & 3.7 \\
\hline a132 & 14592.192 & 14592.190 & -0.1 \\
\hline$(a+1) 133$ & 14730.258 & 14730.210 & -3.3 \\
\hline b134 & 14894.304 & 14894.390 & 5.8 \\
\hline c139 & 15354.532 & 15354.469 & -4.2 \\
\hline$(a+1) 145$ & 16044.842 & 16044.844 & 0.1 \\
\hline$(a+1) 151$ & 16737.119 & 16737.213 & 5.6 \\
\hline a154 & 17081.316 & 17081.408 & 5.3 \\
\hline b156 & 17253.365 & 17253.405 & 2.3 \\
\hline$(a+1) 163$ & 18122.865 & 18122.863 & -0.1 \\
\hline b163 & 18149.852 & 18149.852 & 0.0 \\
\hline
\end{tabular}




\begin{tabular}{|c|c|c|c|}
\hline a163 & 18121.857 & 18121.862 & 0.3 \\
\hline c164 & 18294.973 & 18294.956 & -0.9 \\
\hline a164 & 18249.952 & 18249.949 & -0.1 \\
\hline b164 & 18277.947 & 18277.949 & 0.1 \\
\hline$(a+1) 164$ & 18250.960 & 18250.964 & 0.2 \\
\hline a165 & 18347.004 & 18346.990 & -0.8 \\
\hline$(a+1) 165$ & 18348.012 & 18348.011 & -0.1 \\
\hline b165 & 18374.999 & 18375.010 & 0.6 \\
\hline b170 & 18957.348 & 18957.351 & 0.1 \\
\hline$(a+1) 171$ & 19027.414 & 19027.408 & -0.3 \\
\hline b171 & 19054.401 & 19054.399 & -0.1 \\
\hline a171 & 19026.406 & 19026.407 & 0.0 \\
\hline a172 & 19154.501 & 19154.494 & -0.4 \\
\hline$(a+1) 172$ & 19155.509 & 19155.508 & 0.0 \\
\hline b172 & 19182.496 & 19182.496 & 0.0 \\
\hline$(a+1) 173$ & 19254.577 & 19254.577 & 0.0 \\
\hline a173 & 19253.570 & 19253.574 & 0.2 \\
\hline$(a+1) 174$ & 19410.678 & 19410.680 & 0.1 \\
\hline b175 & 19552.692 & 19552.691 & -0.1 \\
\hline$(a+1) 175$ & 19525.705 & 19525.708 & 0.1 \\
\hline$(a+1) 176$ & 19653.764 & 19653.758 & -0.3 \\
\hline a177 & 19781.799 & 19781.801 & 0.1 \\
\hline$(a+1) 177$ & 19782.807 & 19782.821 & 0.7 \\
\hline$(a+1) 178$ & 19839.828 & 19839.829 & 0.1 \\
\hline a178 & 19838.820 & 19838.825 & 0.2 \\
\hline a179 & 19994.921 & 19994.921 & 0.0 \\
\hline b179 & 20022.916 & 20022.919 & 0.1 \\
\hline$(a+1) 181$ & 20241.013 & 20241.010 & -0.1 \\
\hline $\mathrm{a} 181$ & 20240.005 & 20240.010 & 0.3 \\
\hline$(a+1) 183$ & 20567.139 & 20567.141 & 0.1 \\
\hline b183 & 20594.126 & 20594.132 & 0.3 \\
\hline c184 & 20797.232 & 20797.308 & 3.7 \\
\hline a184 & 20752.211 & 20752.291 & 3.9 \\
\hline$(a+1) 186$ & 20967.350 & 20967.461 & 5.3 \\
\hline$(a+1) 187$ & 21066.419 & 21066.433 & 0.7 \\
\hline
\end{tabular}




\begin{tabular}{|c|c|c|c|}
\hline b188 & 21222.448 & 21222.572 & 5.8 \\
\hline a189 & 21291.506 & 21291.616 & 5.1 \\
\hline c190 & 21393.549 & 21393.663 & 5.4 \\
\hline a191 & 21463.555 & 21463.672 & 5.5 \\
\hline c192 & 21636.671 & 21636.783 & 5.2 \\
\hline a193 & 21704.734 & 21704.821 & 4.0 \\
\hline c193 & 21749.755 & 21749.857 & 4.7 \\
\hline$(a+1) 193$ & 21705.741 & 21705.871 & 6.0 \\
\hline a198 & 22253.977 & 22254.038 & 2.8 \\
\hline$(a+1) 199$ & 22312.006 & 22312.094 & 3.9 \\
\hline c200 & 22470.063 & 22470.130 & 3.0 \\
\hline$(a+1) 200$ & 22426.049 & 22426.161 & 5.0 \\
\hline a202 & 22637.194 & 22637.288 & 4.1 \\
\hline c203 & 22781.284 & 22781.393 & 4.8 \\
\hline a204 & 22833.315 & 22833.365 & 2.2 \\
\hline $\mathrm{a} 205$ & 22989.416 & 22989.533 & 5.1 \\
\hline$(a+1) 207$ & 23224.524 & 23224.652 & 5.5 \\
\hline b209 & 23469.617 & 23469.574 & -1.8 \\
\hline a210 & 23572.663 & 23572.659 & -0.2 \\
\hline a213 & 23971.849 & 23971.925 & 3.2 \\
\hline a214 & 24042.886 & 24042.973 & 3.6 \\
\hline $\mathrm{c} 214$ & 24087.908 & 24087.995 & 3.6 \\
\hline b216 & 24214.935 & 24214.795 & -5.8 \\
\hline a216 & 24186.940 & 24187.037 & 4.0 \\
\hline a217 & 24243.961 & 24244.083 & 5.0 \\
\hline c218 & 24426.041 & 24426.169 & 5.2 \\
\hline$(a+1) 218$ & 24382.028 & 24382.068 & 1.6 \\
\hline$(a+1) 220$ & 24656.146 & 24656.276 & 5.3 \\
\hline b222 & 24957.251 & 24957.243 & -0.3 \\
\hline$(a+1) 222$ & 24930.264 & 24930.259 & -0.2 \\
\hline a222 & 24929.256 & 24929.363 & 4.3 \\
\hline$(a+1) 223$ & 25067.323 & 25067.440 & 4.7 \\
\hline b223 & 25094.310 & 25094.451 & 5.6 \\
\hline z15 & 1769.762 & 1769.754 & -4.5 \\
\hline$(y-1) 16$ & 1915.813 & 1915.816 & 1.2 \\
\hline
\end{tabular}




\begin{tabular}{|c|c|c|c|}
\hline$(x+1) 17$ & 2014.845 & 2014.857 & 5.8 \\
\hline$(y-1) 18$ & 2133.919 & 2133.916 & -1.1 \\
\hline z18 & 2118.908 & 2118.909 & 0.5 \\
\hline$(y-1) 19$ & 2204.956 & 2204.950 & -2.7 \\
\hline$(x+1) 20$ & 2396.014 & 2396.026 & 4.8 \\
\hline $\mathrm{z} 22$ & 2606.162 & 2606.166 & 1.4 \\
\hline y23 & 2721.249 & 2721.236 & $\overline{-5.0}$ \\
\hline$(y-1) 23$ & 2720.241 & 2720.244 & 1.1 \\
\hline $\mathrm{z} 30$ & 3389.575 & 3389.557 & $\begin{array}{l}-5.1 \\
\end{array}$ \\
\hline y33 & 3766.794 & 3766.815 & 5.7 \\
\hline$(x+1) 44$ & 5145.426 & 5145.420 & -1.2 \\
\hline $\mathrm{x} 44$ & 5144.418 & 5144.427 & 1.8 \\
\hline$(y-1) 46$ & 5362.514 & 5362.512 & -0.4 \\
\hline y46 & 5363.522 & 5363.524 & 0.4 \\
\hline $\mathrm{x} 46$ & 5389.501 & 5389.504 & 0.5 \\
\hline $\mathrm{x} 50$ & 5859.725 & 5859.725 & 0.0 \\
\hline$(\mathrm{x}+1) 50$ & 5860.733 & 5860.734 & 0.2 \\
\hline$(\mathrm{y}-1) 50$ & 5832.738 & 5832.741 & 0.5 \\
\hline y50 & 5833.746 & 5833.778 & 5.6 \\
\hline $\mathrm{z} 50$ & 5817.727 & 5817.760 & 5.7 \\
\hline$(\mathrm{y}-1) 51$ & 5947.765 & 5947.761 & -0.6 \\
\hline $\mathrm{x} 51$ & 5974.752 & 5974.750 & -0.3 \\
\hline y51 & 5948.773 & 5948.774 & 0.2 \\
\hline$(x+1) 51$ & 5975.760 & 5975.765 & 0.9 \\
\hline y52 & 6104.874 & 6104.872 & -0.3 \\
\hline$(y-1) 52$ & 6103.866 & 6103.876 & 1.7 \\
\hline$(\mathrm{y}-1) 54$ & 6331.029 & 6331.031 & 0.3 \\
\hline $\mathrm{x} 54$ & 6358.016 & 6358.024 & 1.2 \\
\hline y54 & 6332.037 & 6332.049 & 1.9 \\
\hline$(x+1) 57$ & 6725.262 & 6725.261 & -0.2 \\
\hline y57 & 6698.275 & 6698.274 & $\begin{array}{l}-0.1 \\
\end{array}$ \\
\hline$x 57$ & 6724.254 & 6724.255 & 0.1 \\
\hline$(y-1) 57$ & 6697.267 & 6697.271 & 0.6 \\
\hline$(x+1) 62$ & 7263.574 & 7263.573 & -0.1 \\
\hline$(y-1) 62$ & 7235.579 & 7235.581 & 0.3 \\
\hline
\end{tabular}




\begin{tabular}{|c|c|c|c|}
\hline y62 & 7236.586 & 7236.591 & 0.6 \\
\hline x62 & 7262.566 & 7262.574 & 1.1 \\
\hline z64 & 7495.731 & 7495.755 & 3.2 \\
\hline$(y-1) 64$ & 7510.742 & 7510.769 & 3.5 \\
\hline$(x+1) 65$ & 7666.832 & 7666.799 & -4.3 \\
\hline z65 & 7623.826 & 7623.835 & 1.2 \\
\hline$(y-1) 65$ & 7638.837 & 7638.863 & 3.4 \\
\hline y65 & 7639.845 & 7639.877 & 4.3 \\
\hline x66 & 7752.856 & 7752.878 & 2.8 \\
\hline$(y-1) 67$ & 7888.932 & 7888.966 & 4.3 \\
\hline z67 & 7873.921 & 7873.966 & 5.7 \\
\hline y68 & 8046.041 & 8046.087 & 5.6 \\
\hline z69 & 8117.055 & 8117.019 & -4.3 \\
\hline $\mathrm{z} 70$ & 8204.087 & 8204.088 & 0.2 \\
\hline $\mathrm{x} 70$ & 8246.085 & 8246.087 & 0.3 \\
\hline $\mathrm{z} 72$ & 8360.176 & 8360.154 & -2.7 \\
\hline $\mathrm{y} 72$ & 8376.195 & 8376.163 & -3.9 \\
\hline $\mathrm{x} 72$ & 8402.174 & 8402.172 & -0.3 \\
\hline$y 73$ & 8523.264 & 8523.224 & -4.6 \\
\hline $\mathrm{x} 74$ & 8648.311 & 8648.328 & 1.9 \\
\hline$(y-1) 75$ & 8784.388 & 8784.397 & 1.1 \\
\hline$(y-1) 76$ & 8885.435 & 8885.486 & 5.7 \\
\hline$(y-1) 77$ & 9000.462 & 9000.478 & 1.8 \\
\hline$(x+1) 77$ & 9028.457 & 9028.495 & 4.2 \\
\hline y77 & 9001.470 & 9001.511 & 4.6 \\
\hline $\mathrm{y} 78$ & 9072.507 & 9072.520 & 1.4 \\
\hline$(x+1) 78$ & 9099.494 & 9099.534 & 4.3 \\
\hline$(y-1) 79$ & 9185.542 & 9185.594 & 5.7 \\
\hline y81 & 9477.672 & 9477.690 & 1.9 \\
\hline$(x+1) 81$ & 9504.659 & 9504.705 & 4.9 \\
\hline$(y-1) 83$ & 9676.780 & 9676.805 & 2.5 \\
\hline $\mathrm{x} 86$ & 10074.911 & 10074.943 & 3.1 \\
\hline$(y-1) 86$ & 10047.924 & 10047.963 & 3.9 \\
\hline$(y-1) 87$ & 10118.961 & 10118.994 & 3.2 \\
\hline y88 & 10207.001 & 10207.013 & 1.2 \\
\hline
\end{tabular}




\begin{tabular}{|c|c|c|c|}
\hline $\mathrm{x} 88$ & 10232.981 & 10233.029 & 4.8 \\
\hline y89 & 10308.049 & 10308.048 & -0.1 \\
\hline$(\mathrm{y}-1) 91$ & 10491.126 & 10491.158 & 3.1 \\
\hline$(y-1) 92$ & 10628.185 & 10628.248 & 6.0 \\
\hline z93 & 10750.233 & 10750.294 & 5.7 \\
\hline y95 & 10936.357 & 10936.311 & -4.2 \\
\hline$(\mathrm{y}-1) 95$ & 10935.349 & 10935.399 & 4.5 \\
\hline$(x+1) 96$ & 11149.423 & 11149.423 & 0.0 \\
\hline x96 & 11148.416 & 11148.433 & 1.6 \\
\hline x97 & 11261.500 & 11261.511 & 1.0 \\
\hline x98 & 11360.568 & 11360.624 & 4.9 \\
\hline y99 & 11447.673 & 11447.698 & 2.2 \\
\hline$(y-1) 103$ & 11859.892 & 11859.887 & -0.4 \\
\hline$(y-1) 104$ & 11987.987 & 11988.012 & 2.0 \\
\hline y105 & 12104.022 & 12104.068 & 3.8 \\
\hline y108 & 12494.213 & 12494.249 & 2.9 \\
\hline$(y-1) 108$ & 12493.205 & 12493.278 & 5.8 \\
\hline$(x+1) 109$ & 12608.232 & 12608.197 & -2.7 \\
\hline y111 & 12796.372 & 12796.297 & -5.9 \\
\hline $\mathrm{x} 111$ & 12822.351 & 12822.317 & -2.6 \\
\hline$(y-1) 111$ & 12795.364 & 12795.377 & 1.0 \\
\hline y115 & 13297.667 & 13297.726 & 4.5 \\
\hline $\mathrm{z} 116$ & 13368.680 & 13368.755 & 5.6 \\
\hline$(y-1) 116$ & 13383.691 & 13383.771 & 6.0 \\
\hline y118 & 13555.763 & 13555.726 & -2.7 \\
\hline y119 & 13683.858 & 13683.906 & 3.5 \\
\hline$(y-1) 121$ & 13910.014 & 13910.092 & 5.6 \\
\hline $\mathrm{x} 122$ & 14050.085 & 14050.138 & 3.8 \\
\hline$(y-1) 124$ & 14322.261 & 14322.311 & 3.5 \\
\hline$(x+1) 125$ & 14463.340 & 14463.257 & -5.7 \\
\hline $\mathrm{x} 125$ & 14462.332 & 14462.271 & -4.2 \\
\hline $\mathrm{x} 128$ & 14867.533 & 14867.556 & 1.5 \\
\hline z137 & 15722.939 & 15722.975 & 2.3 \\
\hline $\mathrm{x} 142$ & 16164.149 & 16164.213 & 3.9 \\
\hline$(y-1) 150$ & 17115.593 & 17115.679 & 5.0 \\
\hline
\end{tabular}




\begin{tabular}{|c|c|c|c|}
\hline $\mathrm{x} 151$ & 17229.612 & 17229.524 & -5.1 \\
\hline $\mathrm{y} 158$ & 18006.055 & 18005.972 & -4.6 \\
\hline $\mathrm{y} 159$ & 18153.124 & 18153.048 & -4.1 \\
\hline$(x+1) 159$ & 18180.111 & 18180.042 & -3.8 \\
\hline$(y-1) 167$ & 19031.525 & 19031.578 & 2.8 \\
\hline $\mathrm{x} 168$ & 19171.596 & 19171.549 & -2.4 \\
\hline$(x+1) 168$ & 19172.604 & 19172.589 & -0.8 \\
\hline y170 & 19402.718 & 19402.825 & 5.5 \\
\hline$(x+1) 171$ & 19585.806 & 19585.845 & 2.0 \\
\hline$(\mathrm{y}-1) 171$ & 19557.811 & 19557.865 & 2.8 \\
\hline $\mathrm{z} 172$ & 19655.884 & 19655.910 & 1.3 \\
\hline$(y-1) 172$ & 19670.895 & 19670.945 & 2.5 \\
\hline y172 & 19671.903 & 19671.970 & 3.4 \\
\hline $\mathrm{x} 172$ & 19697.882 & 19697.957 & 3.8 \\
\hline $\mathrm{x} 173$ & 19826.925 & 19827.010 & 4.3 \\
\hline $\mathrm{y} 174$ & 19929.988 & 19929.970 & -0.9 \\
\hline $\mathrm{x} 177$ & 20347.142 & 20347.164 & 1.1 \\
\hline z177 & 20305.144 & 20305.191 & 2.3 \\
\hline y178 & 20468.231 & 20468.237 & 0.3 \\
\hline$(x+1) 178$ & 20495.218 & 20495.325 & 5.2 \\
\hline z179 & 20567.239 & 20567.141 & -4.8 \\
\hline$(x+1) 179$ & 20610.245 & 20610.316 & 3.4 \\
\hline $\mathrm{y} 180$ & 20640.279 & 20640.319 & 1.9 \\
\hline $\mathrm{x} 180$ & 20666.258 & 20666.332 & 3.6 \\
\hline$(y-1) 180$ & 20639.271 & 20639.365 & 4.6 \\
\hline $\mathrm{z} 180$ & 20624.260 & 20624.372 & 5.4 \\
\hline$(x+1) 181$ & 20764.319 & 20764.266 & -2.5 \\
\hline y181 & 20737.332 & 20737.391 & 2.9 \\
\hline$(\mathrm{y}-1) 181$ & 20736.324 & 20736.440 & 5.6 \\
\hline $\mathrm{z} 182$ & 20884.376 & 20884.385 & 0.4 \\
\hline y182 & 20900.395 & 20900.424 & 1.4 \\
\hline$(y-1) 182$ & 20899.387 & 20899.460 & 3.5 \\
\hline $\mathrm{x} 183$ & 21028.376 & 21028.373 & -0.2 \\
\hline$(x+1) 183$ & 21029.384 & 21029.466 & 3.9 \\
\hline$(y-1) 183$ & 21001.389 & 21001.495 & 5.0 \\
\hline
\end{tabular}




\begin{tabular}{|c|c|c|c|}
\hline $\mathrm{y} 184$ & 21103.444 & 21103.448 & 0.2 \\
\hline$(\mathrm{x}+1) 184$ & 21130.431 & 21130.544 & 5.4 \\
\hline $\mathrm{z} 184$ & 21087.425 & 21087.548 & 5.8 \\
\hline $\mathrm{x} 186$ & 21300.488 & 21300.374 & -5.4 \\
\hline $\mathrm{z} 186$ & 21258.490 & 21258.563 & 3.4 \\
\hline $\mathrm{y} 188$ & 21476.568 & 21476.576 & 0.4 \\
\hline $\mathrm{y} 193$ & 21989.811 & 21989.816 & 0.2 \\
\hline$(\mathrm{y}-1) 194$ & 22101.887 & 22101.871 & -0.7 \\
\hline $\mathrm{y} 204$ & 23172.367 & 23172.276 & -3.9 \\
\hline $\mathrm{z} 206$ & 23387.392 & 23387.497 & 4.5 \\
\hline $\mathrm{y} 208$ & 23629.506 & 23629.596 & 3.8 \\
\hline $\mathrm{z} 208$ & 23613.487 & 23613.599 & 4.7 \\
\hline$(\mathrm{x}+1) 222$ & 25132.251 & 25132.256 & 0.2 \\
\hline$(\mathrm{y}-1) 223$ & 25217.340 & 25217.348 & 0.3 \\
\hline$(\mathrm{x}+1) 224$ & 25342.388 & 25342.417 & 1.1 \\
\hline
\end{tabular}


Table S2. List of fragment ions resulting from (A) HCD and (B) UVPD of the 25+ charge state of the D1 H1-17/H3-14 antibody identified as sequence ions corresponding to the (1) light and (2) heavy chains. A \pm 10 ppm mass error was used for identification.

(A) HCD of antibody

(1) Light chain

\begin{tabular}{|c|c|c|c|}
\hline Identified Ion & Theoretical Mass & Observed Mass & Mass Error (ppm) \\
\hline b16 & 1584.811 & 1584.809 & -0.8 \\
\hline b74 & 7842.980 & 7842.993 & 1.6 \\
\hline b102 & 11014.417 & 11014.400 & -1.6 \\
\hline b111 & 11937.936 & 11937.903 & -2.7 \\
\hline b117 & 12628.310 & 12628.384 & 5.9 \\
\hline b118 & 12725.363 & 12725.288 & -5.9 \\
\hline b135 & 14469.222 & 14469.214 & -0.5 \\
\hline y38 & 4211.042 & 4211.075 & 8.1 \\
\hline y44 & 4849.333 & 4849.375 & 8.7 \\
\hline y71 & 7821.744 & 7821.774 & 3.9 \\
\hline y112 & 12282.051 & 12282.024 & -2.2 \\
\hline y122 & 13380.561 & 13380.517 & -3.3 \\
\hline y210 & 22869.226 & 22869.440 & 9.4 \\
\hline
\end{tabular}

(2) Heavy chain

\begin{tabular}{|c|c|c|c|}
\hline Identified Ion & Theoretical Mass & Observed Mass & Mass Error (ppm) \\
\hline b21 & 2178.153 & 2178.148 & -2.5 \\
\hline b63 & 6836.410 & 6836.360 & -7.2 \\
\hline b231 & 24486.171 & 24485.951 & -9.0 \\
\hline b246 & 25957.830 & 25958.020 & 7.3 \\
\hline b307 & 32965.312 & 32965.185 & -3.8 \\
\hline b320 & 34461.163 & 34461.171 & 0.3 \\
\hline b333 & 36010.910 & 36010.809 & -2.8 \\
\hline b345 & 37286.665 & 37286.484 & -4.9 \\
\hline b387 & 41928.079 & 41928.448 & 8.8 \\
\hline y59 & 6727.278 & 6727.220 & -8.5 \\
\hline y87 & 9816.782 & 9816.870 & 9.0 \\
\hline y100 & 11316.544 & 11316.546 & 0.2 \\
\hline$y 107$ & 12108.968 & 12108.936 & -2.6 \\
\hline y108 & 12180.005 & 12180.002 & -0.3 \\
\hline
\end{tabular}




\begin{tabular}{|c|c|c|c|}
\hline y247 & 27773.853 & 27773.957 & 3.8 \\
\hline y254 & 28550.260 & 28550.119 & -4.9 \\
\hline y261 & 29207.593 & 29207.796 & 6.9 \\
\hline y282 & 31324.672 & 31324.719 & 1.5 \\
\hline y292 & 32367.217 & 32367.405 & 5.8 \\
\hline y295 & 32692.381 & 32692.314 & -2.0 \\
\hline y317 & 34858.435 & 34858.518 & 2.4 \\
\hline y329 & 36014.064 & 36014.103 & 1.1 \\
\hline y373 & 40814.313 & 40813.938 & -9.2 \\
\hline y383 & 41917.874 & 41917.751 & -2.9 \\
\hline y385 & 42117.990 & 42117.694 & -7.0 \\
\hline y423 & 46540.260 & 46540.399 & 3.0 \\
\hline y439 & 48004.924 & 48004.812 & -2.3 \\
\hline
\end{tabular}

(B) UVPD of antibody

(1) Light chain

\begin{tabular}{|c|c|c|c|}
\hline Identified Ion & Theoretical Mass & Observed Mass & Mass Error (ppm) \\
\hline $\mathrm{b} 13$ & 1341.689 & 1341.678 & -8.0 \\
\hline $\mathrm{b} 14$ & 1428.721 & 1428.721 & 0.3 \\
\hline $\mathrm{b} 16$ & 1584.811 & 1584.803 & -4.6 \\
\hline$(\mathrm{a}+1) 17$ & 1672.851 & 1672.843 & -4.7 \\
\hline $\mathrm{c} 17$ & 1716.864 & 1716.860 & -2.2 \\
\hline $\mathrm{b} 18$ & 1855.939 & 1855.930 & -4.7 \\
\hline $\mathrm{c} 23$ & 2389.214 & 2389.197 & -7.3 \\
\hline $\mathrm{b} 23$ & 2372.188 & 2372.193 & 2.0 \\
\hline $\mathrm{b} 24$ & 2528.289 & 2528.271 & -7.0 \\
\hline$(\mathrm{a}+1) 27$ & 2787.430 & 2787.427 & -1.0 \\
\hline $\mathrm{c} 51$ & 5606.940 & 5606.898 & -7.5 \\
\hline $\mathrm{c} 55$ & 6049.158 & 6049.186 & 4.6 \\
\hline$(\mathrm{a}+1) 59$ & 6345.319 & 6345.338 & 2.9 \\
\hline $\mathrm{c} 60$ & 6476.365 & 6476.377 & 1.9 \\
\hline $\mathrm{a} 62$ & 6734.513 & 6734.580 & 9.9 \\
\hline $\mathrm{a} 63$ & 6821.545 & 6821.487 & -8.5 \\
\hline $\mathrm{c} 65$ & 6980.609 & 6980.561 & -6.9 \\
\hline $\mathrm{a} 65$ & 6935.588 & 6935.606 & 2.6 \\
\hline & & & \\
\hline & & & \\
\hline
\end{tabular}




\begin{tabular}{|c|c|c|c|}
\hline c70 & 7397.759 & 7397.780 & 2.9 \\
\hline$(a+1) 80$ & 8441.337 & 8441.333 & -0.4 \\
\hline a89 & 9559.738 & 9559.816 & 8.1 \\
\hline b90 & 9716.776 & 9716.828 & 5.4 \\
\hline c92 & 9997.913 & 9997.983 & 7.0 \\
\hline b92 & 9980.887 & 9980.971 & 8.4 \\
\hline c94 & 10241.046 & 10240.976 & -6.9 \\
\hline b96 & 10472.136 & 10472.208 & 6.9 \\
\hline c97 & 10546.184 & 10546.229 & 4.3 \\
\hline b100 & 10815.285 & 10815.283 & -0.2 \\
\hline$(a+1) 100$ & 10788.298 & 10788.352 & 5.0 \\
\hline$(a+1) 102$ & 10987.430 & 10987.469 & 3.5 \\
\hline a102 & 10986.422 & 10986.475 & 4.8 \\
\hline c102 & 11031.443 & 11031.498 & 5.0 \\
\hline b102 & 11014.417 & 11014.481 & 5.8 \\
\hline a103 & 11101.449 & 11101.439 & -0.9 \\
\hline c104 & 11259.554 & 11259.609 & 4.9 \\
\hline b104 & 11242.528 & 11242.585 & 5.0 \\
\hline b106 & 11526.724 & 11526.794 & 6.1 \\
\hline c108 & 11715.835 & 11715.870 & 2.9 \\
\hline b108 & 11698.809 & 11698.856 & 4.0 \\
\hline$(a+1) 108$ & 11671.822 & 11671.884 & 5.3 \\
\hline a108 & 11670.814 & 11670.877 & 5.4 \\
\hline a109 & 11741.851 & 11741.890 & 3.3 \\
\hline a110 & 11812.888 & 11812.940 & 4.4 \\
\hline$(a+1) 110$ & 11813.896 & 11813.949 & 4.5 \\
\hline b110 & 11840.883 & 11840.937 & 4.5 \\
\hline b111 & 11937.936 & 11937.986 & 4.2 \\
\hline b112 & 12024.968 & 12025.021 & 4.4 \\
\hline$(a+1) 112$ & 11997.981 & 11998.054 & 6.1 \\
\hline$(a+1) 113$ & 12097.049 & 12096.968 & -6.7 \\
\hline a113 & 12096.042 & 12096.054 & 1.0 \\
\hline b113 & 12124.036 & 12124.103 & 5.5 \\
\hline a114 & 12243.110 & 12243.110 & 0.0 \\
\hline c114 & 12288.131 & 12288.164 & 2.7 \\
\hline
\end{tabular}




\begin{tabular}{|c|c|c|c|}
\hline$(a+1) 115$ & 12357.202 & 12357.253 & 4.1 \\
\hline b115 & 12384.189 & 12384.277 & 7.1 \\
\hline b116 & 12531.257 & 12531.293 & 2.8 \\
\hline$(a+1) 117$ & 12601.323 & 12601.355 & 2.5 \\
\hline a118 & 12697.368 & 12697.347 & -1.6 \\
\hline$(a+1) 118$ & 12698.376 & 12698.379 & 0.2 \\
\hline c120 & 12944.448 & 12944.510 & 4.8 \\
\hline b121 & 13056.464 & 13056.539 & 5.7 \\
\hline c122 & 13201.549 & 13201.565 & 1.2 \\
\hline a122 & 13156.528 & 13156.581 & 4.0 \\
\hline b122 & 13184.523 & 13184.626 & 7.8 \\
\hline b125 & 13512.734 & 13512.763 & 2.2 \\
\hline b128 & 13741.840 & 13741.861 & 1.5 \\
\hline$(a+1) 132$ & 14102.023 & 14101.981 & -3.0 \\
\hline c136 & 14600.291 & 14600.362 & 4.8 \\
\hline b142 & 15346.630 & 15346.622 & -0.5 \\
\hline$(a+1) 143$ & 15447.738 & 15447.778 & 2.6 \\
\hline b147 & 16016.026 & 16016.014 & -0.7 \\
\hline b148 & 16115.094 & 16115.043 & -3.2 \\
\hline$(a+1) 161$ & 17417.687 & 17417.597 & -5.2 \\
\hline a195 & 21224.470 & 21224.415 & -2.6 \\
\hline c196 & 21406.550 & 21406.600 & 2.3 \\
\hline b197 & 21517.583 & 21517.699 & 5.4 \\
\hline$(a+1) 198$ & 21547.617 & 21547.798 & 8.4 \\
\hline c199 & 21704.714 & 21704.722 & 0.3 \\
\hline $\mathrm{a} 202$ & 21930.810 & 21930.859 & 2.2 \\
\hline$(a+1) 202$ & 21931.818 & 21931.913 & 4.3 \\
\hline b202 & 21958.805 & 21958.964 & 7.2 \\
\hline $\mathrm{a} 203$ & 22029.878 & 22029.912 & 1.5 \\
\hline c204 & 22175.947 & 22175.736 & -9.5 \\
\hline c205 & 22304.042 & 22303.990 & -2.3 \\
\hline b205 & 22287.016 & 22287.072 & 2.5 \\
\hline c206 & 22391.074 & 22391.212 & 6.1 \\
\hline a207 & 22493.122 & 22493.097 & -1.1 \\
\hline $\mathrm{a} 208$ & 22607.164 & 22607.210 & 2.0 \\
\hline
\end{tabular}




\begin{tabular}{|c|c|c|c|}
\hline c210 & 22865.308 & 22865.430 & 5.3 \\
\hline$(a+1) 210$ & 22821.295 & 22821.433 & 6.1 \\
\hline $\mathrm{a} 210$ & 22820.287 & 22820.493 & 9.0 \\
\hline$(a+1) 211$ & 22950.337 & 22950.410 & 3.2 \\
\hline$(y-1) 6$ & 722.281 & 722.287 & 9.0 \\
\hline z13 & 1393.630 & 1393.617 & -9.0 \\
\hline $\mathrm{x} 13$ & 1435.628 & 1435.615 & -8.7 \\
\hline y13 & 1409.648 & 1409.653 & 3.4 \\
\hline $\mathrm{x} 17$ & 1870.851 & 1870.847 & -1.9 \\
\hline $\mathrm{z} 20$ & 2158.011 & 2158.011 & 0.0 \\
\hline$(x+1) 53$ & 5865.750 & 5865.729 & -3.6 \\
\hline$(x+1) 55$ & 6122.851 & 6122.891 & 6.4 \\
\hline$(y-1) 57$ & 6295.931 & 6295.875 & -8.9 \\
\hline y57 & 6296.939 & 6296.972 & 5.3 \\
\hline$(y-1) 61$ & 6681.127 & 6681.187 & 8.9 \\
\hline z66 & 7193.387 & 7193.336 & -7.1 \\
\hline x68 & 7549.523 & 7549.548 & 3.4 \\
\hline y68 & 7523.543 & 7523.535 & -1.1 \\
\hline z68 & 7507.525 & 7507.560 & 4.7 \\
\hline$(x+1) 69$ & 7649.599 & 7649.571 & -3.6 \\
\hline$(x+1) 77$ & 8655.102 & 8655.129 & 3.1 \\
\hline x94 & 10397.953 & 10398.055 & 9.8 \\
\hline $\mathrm{x} 107$ & 11752.693 & 11752.783 & 7.7 \\
\hline$(y-1) 108$ & 11853.801 & 11853.909 & 9.1 \\
\hline z109 & 11951.874 & 11951.893 & 1.6 \\
\hline $\mathrm{x} 110$ & 12108.899 & 12108.851 & -4.0 \\
\hline$(x+1) 110$ & 12109.906 & 12110.025 & 9.8 \\
\hline$(y-1) 113$ & 12382.091 & 12382.077 & -1.1 \\
\hline z113 & 12367.080 & 12367.159 & 6.4 \\
\hline y113 & 12383.099 & 12383.210 & 9.0 \\
\hline z119 & 13013.399 & 13013.290 & -8.4 \\
\hline$(y-1) 121$ & 13278.505 & 13278.588 & 6.2 \\
\hline$(y-1) 128$ & 14165.830 & 14165.843 & 0.9 \\
\hline z131 & 14483.951 & 14484.008 & 3.9 \\
\hline$(x+1) 131$ & 14526.957 & 14527.037 & 5.5 \\
\hline
\end{tabular}




\begin{tabular}{|c|c|c|c|}
\hline y133 & 14726.066 & 14725.991 & -5.1 \\
\hline y137 & 15141.272 & 15141.205 & -4.4 \\
\hline y166 & 18038.728 & 18038.792 & 3.5 \\
\hline$(x+1) 171$ & 18637.063 & 18636.973 & -4.9 \\
\hline z179 & 19623.536 & 19623.555 & 1.0 \\
\hline $\mathrm{z} 185$ & 20266.901 & 20266.721 & -8.9 \\
\hline$(x+1) 186$ & 20437.965 & 20437.909 & -2.8 \\
\hline x187 & 20523.990 & 20524.168 & 8.7 \\
\hline$(x+1) 193$ & 21169.316 & 21169.448 & 6.2 \\
\hline y195 & 21397.499 & 21397.490 & -0.4 \\
\hline z196 & 21496.507 & 21496.317 & -8.8 \\
\hline z198 & 21652.597 & 21652.465 & -6.1 \\
\hline y198 & 21668.616 & 21668.795 & 8.3 \\
\hline y200 & 21826.685 & 21826.840 & 7.1 \\
\hline $\mathrm{x} 200$ & 21852.664 & 21852.846 & 8.3 \\
\hline z201 & 21897.698 & 21897.863 & 7.5 \\
\hline x202 & 22052.780 & 22052.998 & 9.9 \\
\hline z203 & 22097.814 & 22097.907 & 4.2 \\
\hline $\mathrm{z} 204$ & 22184.846 & 22184.890 & 2.0 \\
\hline$(x+1) 204$ & 22227.852 & 22227.994 & 6.4 \\
\hline$(y-1) 204$ & 22199.857 & 22200.027 & 7.7 \\
\hline y204 & 22200.865 & 22201.079 & 9.6 \\
\hline$(y-1) 208$ & 22613.048 & 22613.141 & 4.1 \\
\hline$(x+1) 209$ & 22740.111 & 22740.332 & 9.7 \\
\hline$(y-1) 210$ & 22868.218 & 22868.197 & -0.9 \\
\hline $\mathrm{x} 210$ & 22895.205 & 22895.428 & 9.8 \\
\hline y211 & 22982.310 & 22982.466 & 6.8 \\
\hline
\end{tabular}

(2) Heavy chain

\begin{tabular}{|c|c|c|c|}
\hline Identified Ion & Theoretical Mass & Observed Mass & Mass Error (ppm) \\
\hline $\mathrm{c} 20$ & 2094.132 & 2094.141 & 4.2 \\
\hline $\mathrm{b} 25$ & 2553.287 & 2553.277 & -3.9 \\
\hline $\mathrm{c} 42$ & 4541.288 & 4541.266 & -4.9 \\
\hline$(\mathrm{a}+1) 47$ & 4949.550 & 4949.533 & -3.5 \\
\hline $\mathrm{a} 56$ & 6061.060 & 6061.038 & -3.6 \\
\hline $\mathrm{a} 64$ & 6895.447 & 6895.462 & 2.2 \\
\hline
\end{tabular}




\begin{tabular}{|c|c|c|c|}
\hline a89 & 9526.834 & 9526.798 & -3.7 \\
\hline c91 & 9757.919 & 9757.881 & -3.8 \\
\hline$(a+1) 91$ & 9713.906 & 9713.893 & -1.3 \\
\hline b93 & 9912.977 & 9912.929 & -4.9 \\
\hline b96 & 10338.173 & 10338.150 & -2.1 \\
\hline c99 & 10684.338 & 10684.352 & 1.3 \\
\hline b100 & 10782.339 & 10782.334 & -0.5 \\
\hline $\mathrm{c} 100$ & 10799.365 & 10799.415 & 4.6 \\
\hline$(a+1) 101$ & 10902.420 & 10902.443 & 2.1 \\
\hline b102 & 11076.476 & 11076.482 & 0.5 \\
\hline$(a+1) 103$ & 11178.531 & 11178.514 & -1.6 \\
\hline b103 & 11205.518 & 11205.534 & 1.4 \\
\hline a103 & 11177.524 & 11177.579 & 4.9 \\
\hline$(a+1) 107$ & 11603.832 & 11603.815 & -1.5 \\
\hline c107 & 11647.845 & 11647.902 & 4.9 \\
\hline$(a+1) 108$ & 11718.859 & 11718.890 & 2.7 \\
\hline a108 & 11717.851 & 11717.892 & 3.5 \\
\hline a110 & 11945.962 & 11945.986 & 2.0 \\
\hline a112 & 12131.042 & 12131.058 & 1.4 \\
\hline b112 & 12159.037 & 12159.097 & 4.9 \\
\hline$(a+1) 115$ & 12507.229 & 12507.262 & 2.6 \\
\hline b115 & 12534.216 & 12534.254 & 3.0 \\
\hline c129 & 13943.877 & 13943.897 & 1.4 \\
\hline b133 & 14296.052 & 14296.053 & 0.1 \\
\hline c134 & 14412.146 & 14412.130 & -1.1 \\
\hline$(a+1) 135$ & 14515.201 & 14515.131 & -4.8 \\
\hline b135 & 14542.188 & 14542.143 & -3.1 \\
\hline b136 & 14639.241 & 14639.210 & -2.1 \\
\hline b138 & 14823.362 & 14823.401 & 2.6 \\
\hline$(a+1) 144$ & 15383.667 & 15383.672 & 0.4 \\
\hline c205 & 21547.776 & 21547.798 & 1.0 \\
\hline c207 & 21811.887 & 21811.870 & -0.8 \\
\hline b208 & 21907.944 & 21907.895 & -2.3 \\
\hline$(a+1) 209$ & 21982.959 & 21982.977 & 0.8 \\
\hline c209 & 22026.972 & 22027.034 & 2.8 \\
\hline
\end{tabular}




\begin{tabular}{|c|c|c|c|}
\hline $\mathrm{a} 211$ & 22195.062 & 22195.034 & -1.3 \\
\hline b214 & 22602.254 & 22602.203 & -2.3 \\
\hline c215 & 22716.333 & 22716.377 & 1.9 \\
\hline c218 & 23018.456 & 23018.437 & -0.8 \\
\hline c219 & 23147.498 & 23147.526 & 1.2 \\
\hline$(a+1) 219$ & 23103.485 & 23103.543 & 2.5 \\
\hline$(a+1) 220$ & 23202.553 & 23202.458 & -4.1 \\
\hline c221 & 23361.594 & 23361.549 & -1.9 \\
\hline a224 & 23671.831 & 23671.922 & 3.9 \\
\hline$(a+1) 224$ & 23672.839 & 23672.944 & 4.5 \\
\hline b232 & 24587.219 & 24587.181 & -1.6 \\
\hline c244 & 25860.813 & 25860.783 & -1.2 \\
\hline$(a+1) 268$ & 28411.193 & 28411.133 & -2.1 \\
\hline a276 & 29211.567 & 29211.637 & 2.4 \\
\hline b280 & 29717.743 & 29717.820 & 2.6 \\
\hline c283 & 30090.975 & 30090.887 & -2.9 \\
\hline $\mathrm{a} 283$ & 30045.954 & 30045.877 & -2.6 \\
\hline$(a+1) 286$ & 30494.152 & 30494.058 & -3.1 \\
\hline c289 & 30915.325 & 30915.191 & -4.3 \\
\hline$(a+1) 290$ & 30928.333 & 30928.402 & 2.3 \\
\hline$(a+1) 293$ & 31255.512 & 31255.434 & -2.5 \\
\hline$(a+1) 310$ & 33358.537 & 33358.533 & -0.1 \\
\hline$(a+1) 313$ & 33643.705 & 33643.764 & 1.7 \\
\hline b314 & 33769.761 & 33769.664 & -2.9 \\
\hline a321 & 34548.195 & 34548.283 & 2.6 \\
\hline c324 & 35006.422 & 35006.594 & 4.9 \\
\hline c326 & 35191.539 & 35191.510 & -0.8 \\
\hline b327 & 35303.555 & 35303.677 & 3.5 \\
\hline b328 & 35466.618 & 35466.759 & 4.0 \\
\hline a333 & 35982.915 & 35982.929 & 0.4 \\
\hline b344 & 37173.581 & 37173.425 & -4.2 \\
\hline$(a+1) 344$ & 37146.594 & 37146.620 & 0.7 \\
\hline b351 & 37886.004 & 37886.000 & -0.1 \\
\hline b362 & 39163.681 & 39163.726 & 1.2 \\
\hline b374 & 40534.396 & 40534.309 & -2.1 \\
\hline
\end{tabular}




\begin{tabular}{|c|c|c|c|}
\hline c374 & 40551.423 & 40551.487 & 1.6 \\
\hline b376 & 40737.445 & 40737.393 & -1.3 \\
\hline a377 & 40822.534 & 40822.420 & -2.8 \\
\hline$(a+1) 386$ & 41830.055 & 41830.121 & 1.6 \\
\hline$(a+1) 392$ & 42531.357 & 42531.403 & 1.1 \\
\hline$(a+1) 393$ & 42645.400 & 42645.217 & -4.3 \\
\hline$(a+1) 398$ & 43170.618 & 43170.821 & 4.7 \\
\hline c399 & 43328.674 & 43328.503 & -4.0 \\
\hline a402 & 43675.859 & 43675.986 & 2.9 \\
\hline b426 & 46484.271 & 46484.239 & -0.7 \\
\hline $\mathrm{a} 427$ & 46584.335 & 46584.255 & -1.7 \\
\hline a428 & 46641.356 & 46641.192 & -3.5 \\
\hline $\mathrm{c} 428$ & 46686.378 & 46686.563 & 4.0 \\
\hline b435 & 47404.665 & 47404.853 & 4.0 \\
\hline$(a+1) 437$ & 47645.777 & 47645.679 & -2.1 \\
\hline $\mathrm{b} 437$ & 47672.764 & 47672.768 & 0.1 \\
\hline $\mathrm{b} 439$ & 47872.844 & 47873.078 & 4.9 \\
\hline a442 & 48209.035 & 48209.206 & 3.5 \\
\hline$(a+1) 448$ & 48954.398 & 48954.544 & 3.0 \\
\hline$(a+1) 454$ & 49508.705 & 49508.635 & -1.4 \\
\hline $\mathrm{x} 12$ & 1333.688 & 1333.681 & -4.8 \\
\hline z13 & 1428.749 & 1428.750 & 0.9 \\
\hline z19 & 2130.073 & 2130.063 & -4.8 \\
\hline$(x+1) 19$ & 2173.079 & 2173.082 & 1.4 \\
\hline$(y-1) 20$ & 2276.125 & 2276.130 & 2.5 \\
\hline $\mathrm{z} 21$ & 2360.182 & 2360.184 & 0.8 \\
\hline$(x+1) 21$ & 2403.188 & 2403.199 & 4.5 \\
\hline$(y-1) 22$ & 2462.225 & 2462.230 & 2.1 \\
\hline y37 & 4198.035 & 4198.016 & -4.5 \\
\hline$(y-1) 40$ & 4601.270 & 4601.289 & 4.3 \\
\hline $\mathrm{y} 41$ & 4715.361 & 4715.364 & 0.6 \\
\hline$(y-1) 53$ & 5976.936 & 5976.936 & 0.0 \\
\hline y55 & 6207.086 & 6207.093 & 1.1 \\
\hline y61 & 6952.389 & 6952.418 & 4.2 \\
\hline x94 & 10641.148 & 10641.197 & 4.6 \\
\hline
\end{tabular}




\begin{tabular}{|c|c|c|c|}
\hline y100 & 11316.544 & 11316.541 & -0.3 \\
\hline y106 & 11980.873 & 11980.896 & 1.9 \\
\hline$(y-1) 111$ & 12507.209 & 12507.262 & 4.3 \\
\hline $\mathrm{x} 111$ & 12534.196 & 12534.254 & 4.6 \\
\hline z114 & 12850.383 & 12850.364 & -1.4 \\
\hline $\mathrm{x} 115$ & 13005.465 & 13005.446 & -1.5 \\
\hline$(y-1) 116$ & 13075.531 & 13075.510 & -1.6 \\
\hline y116 & 13076.538 & 13076.557 & 1.4 \\
\hline $\mathrm{z} 116$ & 13060.520 & 13060.543 & 1.8 \\
\hline$(x+1) 116$ & 13103.525 & 13103.567 & 3.2 \\
\hline z117 & 13131.557 & 13131.539 & -1.3 \\
\hline $\mathrm{z} 118$ & 13228.610 & 13228.620 & 0.8 \\
\hline y118 & 13244.628 & 13244.643 & 1.1 \\
\hline$(x+1) 119$ & 13384.699 & 13384.712 & 0.9 \\
\hline y121 & 13556.844 & 13556.832 & -0.9 \\
\hline$(x+1) 123$ & 13784.906 & 13784.839 & -4.9 \\
\hline $\mathrm{z} 123$ & 13741.901 & 13741.861 & -2.9 \\
\hline $\mathrm{x} 123$ & 13783.899 & 13783.890 & -0.7 \\
\hline $\mathrm{x} 125$ & 14011.062 & 14011.031 & -2.2 \\
\hline $\mathrm{z} 133$ & 14903.510 & 14903.440 & -4.7 \\
\hline y149 & 16803.518 & 16803.529 & 0.7 \\
\hline $\mathrm{x} 159$ & 18103.139 & 18103.101 & -2.0 \\
\hline$(y-1) 162$ & 18398.290 & 18398.358 & 3.7 \\
\hline y186 & 21142.570 & 21142.558 & -0.5 \\
\hline$(y-1) 190$ & 21567.773 & 21567.731 & -2.0 \\
\hline$(y-1) 191$ & 21668.821 & 21668.795 & -1.2 \\
\hline z192 & 21809.911 & 21809.826 & -3.9 \\
\hline$(x+1) 192$ & 21852.917 & 21852.846 & -3.2 \\
\hline$(\mathrm{y}-1) 192$ & 21824.922 & 21824.860 & -2.8 \\
\hline z193 & 21896.943 & 21896.927 & -0.7 \\
\hline $\mathrm{x} 194$ & 22052.025 & 22051.984 & -1.9 \\
\hline$(x+1) 194$ & 22053.033 & 22053.044 & 0.5 \\
\hline $\mathrm{x} 196$ & 22296.150 & 22296.107 & -1.9 \\
\hline$(y-1) 196$ & 22269.163 & 22269.121 & -1.8 \\
\hline y197 & 22371.218 & 22371.192 & -1.2 \\
\hline
\end{tabular}




\begin{tabular}{|c|c|c|c|}
\hline z198 & 22470.226 & 22470.220 & -0.3 \\
\hline$(x+1) 198$ & 22513.232 & 22513.316 & 3.7 \\
\hline$(y-1) 200$ & 22710.385 & 22710.312 & -3.2 \\
\hline $\mathrm{x} 201$ & 22865.467 & 22865.430 & -1.6 \\
\hline$(x+1) 202$ & 22963.528 & 22963.531 & 0.1 \\
\hline z202 & 22920.522 & 22920.538 & 0.7 \\
\hline$(x+1) 203$ & 23060.580 & 23060.512 & -3.0 \\
\hline y203 & 23033.593 & 23033.574 & -0.8 \\
\hline z204 & 23164.643 & 23164.596 & -2.0 \\
\hline x206 & 23466.793 & 23466.690 & -4.4 \\
\hline$(x+1) 206$ & 23467.801 & 23467.758 & -1.9 \\
\hline z206 & 23424.795 & 23424.789 & -0.3 \\
\hline$(y-1) 206$ & 23439.806 & 23439.825 & 0.8 \\
\hline y207 & 23539.883 & 23539.868 & -0.6 \\
\hline y208 & 23626.915 & 23626.981 & 2.8 \\
\hline$(\mathrm{y}-1) 209$ & 23722.959 & 23722.925 & -1.5 \\
\hline y210 & 23780.989 & 23780.989 & 0.0 \\
\hline $\mathrm{x} 211$ & 23863.989 & 23864.060 & 3.0 \\
\hline$(x+1) 211$ & 23864.997 & 23865.072 & 3.1 \\
\hline $\mathrm{x} 212$ & 23977.074 & 23977.138 & 2.7 \\
\hline $\mathrm{x} 214$ & 24219.200 & 24219.243 & 1.8 \\
\hline z219 & 24641.399 & 24641.358 & -1.7 \\
\hline$(x+1) 224$ & 25222.613 & 25222.665 & 2.1 \\
\hline$x 227$ & 25566.729 & 25566.671 & -2.3 \\
\hline $\mathrm{z} 234$ & 26321.211 & 26321.104 & -4.1 \\
\hline $\mathrm{z} 253$ & 28421.157 & 28421.134 & -0.8 \\
\hline$(y-1) 255$ & 28636.284 & 28636.276 & -0.3 \\
\hline$(x+1) 264$ & 29507.713 & 29507.647 & -2.2 \\
\hline z267 & 29827.886 & 29827.810 & -2.6 \\
\hline $\mathrm{x} 267$ & 29869.884 & 29869.945 & 2.0 \\
\hline $\mathrm{z} 277$ & 30827.425 & 30827.429 & 0.1 \\
\hline $\mathrm{z} 278$ & 30928.473 & 30928.402 & -2.3 \\
\hline y279 & 31081.550 & 31081.619 & 2.2 \\
\hline$(x+1) 280$ & 31207.606 & 31207.596 & -0.3 \\
\hline $\mathrm{z} 281$ & 31221.622 & 31221.659 & 1.2 \\
\hline
\end{tabular}




\begin{tabular}{|c|c|c|c|}
\hline$(y-1) 287$ & 31752.887 & 31752.928 & 1.3 \\
\hline y293 & 32466.285 & 32466.418 & 4.1 \\
\hline x303 & 33682.820 & 33682.759 & -1.8 \\
\hline$(y-1) 307$ & 33968.013 & 33968.109 & 2.8 \\
\hline y315 & 34674.350 & 34674.201 & -4.3 \\
\hline$(y-1) 320$ & 35138.601 & 35138.451 & -4.3 \\
\hline y320 & 35139.609 & 35139.566 & -1.2 \\
\hline$(y-1) 324$ & 35568.823 & 35568.808 & -0.4 \\
\hline z328 & 35927.008 & 35926.923 & -2.4 \\
\hline$(y-1) 331$ & 36187.120 & 36186.993 & -3.5 \\
\hline z331 & 36172.109 & 36172.221 & 3.1 \\
\hline x332 & 36313.175 & 36313.112 & -1.8 \\
\hline$(x+1) 333$ & 36415.231 & 36415.152 & -2.2 \\
\hline$(x+1) 339$ & 36988.489 & 36988.549 & 1.6 \\
\hline $\mathrm{x} 340$ & 37173.561 & 37173.425 & -3.6 \\
\hline$(y-1) 340$ & 37146.573 & 37146.620 & 1.3 \\
\hline $\mathrm{x} 353$ & 38631.301 & 38631.432 & 3.4 \\
\hline$(x+1) 356$ & 39041.472 & 39041.593 & 3.1 \\
\hline x366 & 40152.948 & 40152.913 & -0.9 \\
\hline$(y-1) 367$ & 40196.998 & 40197.076 & 1.9 \\
\hline z370 & 40469.135 & 40469.248 & 2.8 \\
\hline$(x+1) 370$ & 40512.141 & 40512.263 & 3.0 \\
\hline z371 & 40556.167 & 40556.337 & 4.2 \\
\hline$(x+1) 372$ & 40712.257 & 40712.167 & -2.2 \\
\hline y372 & 40685.270 & 40685.415 & 3.6 \\
\hline$(y-1) 372$ & 40684.262 & 40684.448 & 4.6 \\
\hline$(x+1) 383$ & 41944.861 & 41944.751 & -2.6 \\
\hline x384 & 42030.885 & 42031.011 & 3.0 \\
\hline$(x+1) 386$ & 42246.025 & 42245.925 & -2.3 \\
\hline z389 & 42515.210 & 42515.065 & -3.4 \\
\hline y389 & 42531.228 & 42531.403 & 4.1 \\
\hline y390 & 42645.271 & 42645.217 & -1.3 \\
\hline y393 & 42942.440 & 42942.446 & 0.1 \\
\hline y404 & 44220.033 & 44219.909 & -2.8 \\
\hline $\mathrm{z} 405$ & 44261.036 & 44261.231 & 4.4 \\
\hline
\end{tabular}




\begin{tabular}{|c|c|c|c|}
\hline$(\mathrm{x}+1) 405$ & 44304.042 & 44304.250 & 4.7 \\
\hline$(\mathrm{x}+1) 407$ & 44603.205 & 44603.086 & -2.7 \\
\hline $\mathrm{z} 423$ & 46524.241 & 46524.112 & -2.8 \\
\hline$(\mathrm{x}+1) 425$ & 46768.322 & 46768.359 & 0.8 \\
\hline $\mathrm{y} 426$ & 46828.367 & 46828.197 & -3.6 \\
\hline$(\mathrm{y}-1) 433$ & 47400.635 & 47400.682 & 1.0 \\
\hline$(\mathrm{x}+1) 436$ & 47744.763 & 47744.977 & 4.5 \\
\hline$(\mathrm{x}+1) 439$ & 48031.911 & 48032.094 & -3.2 \\
\hline$(\mathrm{y}-1) 442$ & 48317.044 & 48316.887 & -1.2 \\
\hline$(\mathrm{x}+1) 444$ & 48572.202 & 48572.146 & 3.6 \\
\hline$(\mathrm{y}-1) 447$ & 48811.365 & 48811.543 & \\
\hline
\end{tabular}


Table S3. (A) HCD and (B) UVPD fragment ions produced by activation of the 29+ charge state of the 1:2 antibody:antigen complex. The sequences of (1) HA1, as well as the (2) light and (3) heavy chains of the D1 H1-17/H3-14 antibody were searched. The mass error for identification was $\pm 10 \mathrm{ppm}$.

\section{(A) HCD of 1:2 antibody:antigen complex}

(1) HA1

\begin{tabular}{|c|c|c|c|}
\hline Identified Ion & Theoretical Mass & Observed Mass & Mass Error (ppm) \\
\hline b21 & 2214.071 & 2214.072 & 0.2 \\
\hline $\mathrm{b} 22$ & 2301.103 & 2301.115 & 5.1 \\
\hline b23 & 2414.187 & 2414.190 & 1.1 \\
\hline b24 & 2501.219 & 2501.237 & 6.9 \\
\hline b31 & 3283.543 & 3283.537 & -1.8 \\
\hline b32 & 3396.627 & 3396.628 & 0.3 \\
\hline b34 & 3624.738 & 3624.734 & -1.0 \\
\hline b35 & 3725.786 & 3725.786 & 0.0 \\
\hline b39 & 4111.930 & 4111.931 & 0.4 \\
\hline b108 & 11887.696 & 11887.693 & -0.3 \\
\hline b126 & 13938.765 & 13938.777 & 0.9 \\
\hline b127 & 14051.849 & 14051.781 & -4.8 \\
\hline b140 & 15452.533 & 15452.439 & -6.1 \\
\hline b142 & 15708.650 & 15708.582 & -4.3 \\
\hline b143 & 15795.682 & 15795.696 & 0.9 \\
\hline b178 & 19866.815 & 19866.856 & 2.1 \\
\hline b188 & 21222.448 & 21222.367 & -3.9 \\
\hline y12 & 1386.594 & 1386.595 & 1.1 \\
\hline y14 & 1656.738 & 1656.740 & 1.3 \\
\hline $\mathrm{y} 27$ & 3104.466 & 3104.476 & 3.3 \\
\hline y29 & 3276.551 & 3276.552 & 0.2 \\
\hline $\mathrm{y} 32$ & 3653.710 & 3653.711 & 0.3 \\
\hline y33 & 3766.794 & 3766.802 & 2.2 \\
\hline y34 & 3894.889 & 3894.892 & 0.9 \\
\hline y37 & 4163.990 & 4163.995 & 1.3 \\
\hline y38 & 4293.032 & 4293.040 & 1.8 \\
\hline $\mathrm{y} 40$ & 4505.185 & 4505.176 & -2.0 \\
\hline $\mathrm{y} 48$ & 5576.644 & 5576.642 & -0.4 \\
\hline $\mathrm{y} 50$ & 5833.746 & 5833.756 & 1.7 \\
\hline
\end{tabular}




\begin{tabular}{|c|c|c|c|}
\hline y61 & 7108.492 & 7108.462 & -4.2 \\
\hline y76 & 8886.443 & 8886.460 & 1.9 \\
\hline y77 & 9001.470 & 9001.534 & 7.2 \\
\hline y78 & 9072.507 & 9072.518 & 1.2 \\
\hline y79 & 9186.550 & 9186.552 & 0.2 \\
\hline y80 & 9314.609 & 9314.608 & 0.0 \\
\hline y81 & 9477.672 & 9477.676 & 0.4 \\
\hline y83 & 9677.788 & 9677.787 & -0.1 \\
\hline y85 & 9933.905 & 9933.902 & -0.3 \\
\hline y90 & 10395.081 & 10395.090 & 0.8 \\
\hline y91 & 10492.134 & 10492.125 & -0.8 \\
\hline y92 & 10629.193 & 10629.201 & 0.8 \\
\hline y93 & 10766.252 & 10766.250 & -0.2 \\
\hline y96 & 11122.436 & 11122.439 & 0.2 \\
\hline$y 104$ & 11988.995 & 11988.957 & -3.2 \\
\hline y107 & 12331.149 & 12331.122 & -2.2 \\
\hline y116 & 13384.699 & 13384.727 & 2.1 \\
\hline y185 & 21160.466 & 21160.412 & -2.5 \\
\hline
\end{tabular}

(2) Light chain of antibody

\begin{tabular}{|c|c|c|c|}
\hline Identified Ion & Theoretical Mass & Observed Mass & Mass Error (ppm) \\
\hline b14 & 1428.721 & 1428.724 & 2.0 \\
\hline b15 & 1527.789 & 1527.777 & -8.2 \\
\hline b16 & 1584.811 & 1584.810 & -0.3 \\
\hline b18 & 1855.939 & 1855.928 & -6.0 \\
\hline b30 & 3101.565 & 3101.550 & -4.8 \\
\hline b82 & 8712.393 & 8712.378 & -1.8 \\
\hline b88 & 9459.674 & 9459.689 & 1.6 \\
\hline b111 & 11937.936 & 11937.935 & 0.0 \\
\hline b113 & 12124.036 & 12123.997 & -3.3 \\
\hline b114 & 12271.105 & 12270.993 & -9.1 \\
\hline y14 & 1522.732 & 1522.745 & 8.0 \\
\hline y66 & 7209.405 & 7209.364 & -5.7 \\
\hline y109 & 11967.892 & 11967.953 & 5.1 \\
\hline y113 & 12383.099 & 12383.099 & 0.0 \\
\hline y115 & 12568.179 & 12568.197 & 1.4 \\
\hline
\end{tabular}




\begin{tabular}{|c|c|c|c|}
\hline $\mathrm{y} 116$ & 12625.201 & 12625.265 & 5.1 \\
\hline $\mathrm{y} 126$ & 13902.727 & 13902.739 & 0.9 \\
\hline $\mathrm{y} 157$ & 17065.205 & 17065.124 & -4.7 \\
\hline
\end{tabular}

(3) Heavy chain of antibody

\begin{tabular}{|c|c|c|c|}
\hline Identified Ion & Theoretical Mass & Observed Mass & Mass Error (ppm) \\
\hline b21 & 2178.153 & 2178.153 & 0.1 \\
\hline b44 & 4678.336 & 4678.363 & 5.7 \\
\hline b112 & 12159.037 & 12159.082 & 3.7 \\
\hline b239 & 25320.486 & 25320.474 & -0.5 \\
\hline b240 & 25391.524 & 25391.534 & 0.4 \\
\hline b245 & 25900.809 & 25900.573 & -9.1 \\
\hline b294 & 31419.558 & 31419.628 & 2.2 \\
\hline b315 & 33882.845 & 33882.920 & 2.2 \\
\hline b322 & 34762.269 & 34762.128 & -4.1 \\
\hline y14 & 1558.810 & 1558.804 & -4.4 \\
\hline y15 & 1695.869 & 1695.868 & -0.5 \\
\hline y20 & 2277.132 & 2277.118 & -6.3 \\
\hline y58 & 6598.235 & 6598.223 & -1.9 \\
\hline y88 & 9917.830 & 9917.908 & 7.9 \\
\hline y99 & 11188.485 & 11188.478 & -0.6 \\
\hline y104 & 11795.793 & 11795.696 & -8.2 \\
\hline y108 & 12180.005 & 12180.088 & 6.8 \\
\hline y121 & 13556.844 & 13556.756 & -6.5 \\
\hline y142 & 16011.105 & 16011.045 & -3.7 \\
\hline y242 & 27207.638 & 27207.831 & 7.1 \\
\hline y243 & 27344.697 & 27344.933 & 8.6 \\
\hline y289 & 32054.017 & 32053.837 & -5.6 \\
\hline y318 & 34929.472 & 34929.174 & -8.5 \\
\hline y335 & 36618.353 & 36618.562 & 5.7 \\
\hline y445 & 48658.299 & 48658.102 & -4.0 \\
\hline
\end{tabular}

(B) UVPD of 1:2 antibody:antigen complex

(1) HA1

\begin{tabular}{|c|c|c|c|}
\hline Identified Ion & Theoretical Mass & Observed Mass & Mass Error (ppm) \\
\hline b16 & 1642.889 & 1642.883 & -3.6 \\
\hline$(\mathrm{a}+1) 16$ & 1615.902 & 1615.911 & 5.6 \\
\hline
\end{tabular}




\begin{tabular}{|c|c|c|c|}
\hline$(a+1) 18$ & 1826.998 & 1827.008 & 5.9 \\
\hline a20 & 2057.034 & 2057.036 & 1.2 \\
\hline$(a+1) 21$ & 2187.084 & 2187.092 & 3.4 \\
\hline $\mathrm{c} 22$ & 2318.130 & 2318.140 & 4.3 \\
\hline b23 & 2414.187 & 2414.173 & -5.9 \\
\hline c24 & 2518.246 & 2518.242 & -1.6 \\
\hline c66 & 7250.341 & 7250.302 & -5.3 \\
\hline b95 & 10310.784 & 10310.752 & -3.1 \\
\hline b103 & 11362.333 & 11362.285 & -4.2 \\
\hline b113 & 12476.982 & 12477.051 & 5.5 \\
\hline c118 & 13072.315 & 13072.259 & -4.3 \\
\hline$(a+1) 119$ & 13141.386 & 13141.481 & 7.2 \\
\hline b122 & 13525.538 & 13525.474 & -4.7 \\
\hline c126 & 13955.792 & 13955.764 & -2.0 \\
\hline$(a+1) 126$ & 13911.778 & 13911.798 & 1.5 \\
\hline a126 & 13910.770 & 13910.798 & 2.0 \\
\hline$(a+1) 127$ & 14024.862 & 14024.868 & 0.4 \\
\hline c127 & 14068.876 & 14068.885 & 0.7 \\
\hline a127 & 14023.854 & 14023.943 & 6.3 \\
\hline$(a+1) 128$ & 14123.931 & 14123.947 & 1.2 \\
\hline a128 & 14122.923 & 14122.921 & -0.2 \\
\hline b128 & 14150.918 & 14150.958 & 2.8 \\
\hline$(a+1) 129$ & 14237.015 & 14237.061 & 3.3 \\
\hline a129 & 14236.007 & 14236.061 & 3.8 \\
\hline c131 & 14524.129 & 14524.127 & -0.1 \\
\hline$(a+1) 131$ & 14480.115 & 14480.177 & 4.3 \\
\hline c133 & 14774.272 & 14774.207 & -4.4 \\
\hline$(a+1) 134$ & 14867.317 & 14867.349 & 2.2 \\
\hline a134 & 14866.309 & 14866.254 & -3.7 \\
\hline a137 & 15151.442 & 15151.349 & -6.1 \\
\hline b138 & 15266.469 & 15266.460 & -0.6 \\
\hline a140 & 15424.538 & 15424.583 & 2.9 \\
\hline$(a+1) 141$ & 15553.604 & 15553.638 & 2.2 \\
\hline a141 & 15552.597 & 15552.638 & 2.7 \\
\hline$(a+1) 142$ & 15681.663 & 15681.678 & 1.0 \\
\hline
\end{tabular}




\begin{tabular}{|c|c|c|c|}
\hline c145 & 16088.856 & 16088.844 & -0.8 \\
\hline a146 & 16171.893 & 16171.914 & 1.3 \\
\hline c146 & 16216.914 & 16216.961 & 2.8 \\
\hline c147 & 16330.957 & 16330.915 & -2.6 \\
\hline b149 & 16499.995 & 16500.019 & 1.5 \\
\hline a154 & 17081.316 & 17081.298 & -1.1 \\
\hline$(a+1) 155$ & 17139.346 & 17139.464 & 6.9 \\
\hline c157 & 17357.423 & 17357.413 & -0.6 \\
\hline b183 & 20594.126 & 20594.073 & -2.6 \\
\hline$(a+1) 184$ & 20753.219 & 20753.357 & 6.7 \\
\hline a186 & 20966.342 & 20966.488 & 6.9 \\
\hline c189 & 21336.527 & 21336.549 & 1.0 \\
\hline$(a+1) 191$ & 21464.562 & 21464.603 & 1.9 \\
\hline a192 & 21591.650 & 21591.748 & 4.6 \\
\hline a195 & 21952.850 & 21952.874 & 1.1 \\
\hline$(a+1) 197$ & 22153.937 & 22154.098 & 7.3 \\
\hline$(a+1) 198$ & 22254.985 & 22254.873 & -5.0 \\
\hline$(a+1) 200$ & 22426.049 & 22426.083 & 1.5 \\
\hline a200 & 22425.041 & 22425.221 & 8.0 \\
\hline b201 & 22566.120 & 22566.100 & -0.9 \\
\hline$(a+1) 202$ & 22638.202 & 22638.383 & 8.0 \\
\hline c204 & 22878.336 & 22878.506 & 7.4 \\
\hline c206 & 23197.501 & 23197.356 & -6.2 \\
\hline b206 & 23180.474 & 23180.484 & 0.4 \\
\hline a206 & 23152.480 & 23152.599 & 5.2 \\
\hline c207 & 23268.538 & 23268.630 & 4.0 \\
\hline a209 & 23441.622 & 23441.644 & 0.9 \\
\hline b210 & 23600.658 & 23600.764 & 4.5 \\
\hline b211 & 23729.700 & 23729.567 & -5.6 \\
\hline c213 & 24016.871 & 24017.019 & 6.2 \\
\hline c215 & 24144.929 & 24144.962 & 1.4 \\
\hline $\mathrm{b} 216$ & 24214.935 & 24214.867 & -2.8 \\
\hline$(a+1) 216$ & 24187.948 & 24188.050 & 4.2 \\
\hline b217 & 24271.956 & 24272.101 & 5.9 \\
\hline c218 & 24426.041 & 24425.861 & -7.4 \\
\hline
\end{tabular}




\begin{tabular}{|c|c|c|c|}
\hline a218 & 24381.020 & 24380.940 & -3.3 \\
\hline c220 & 24700.159 & 24700.103 & -2.3 \\
\hline a220 & 24655.138 & 24655.085 & -2.2 \\
\hline$(a+1) 224$ & 25204.382 & 25204.474 & 3.6 \\
\hline b224 & 25231.369 & 25231.545 & 7.0 \\
\hline z6 & 824.345 & 824.346 & 1.1 \\
\hline y6 & 840.364 & 840.361 & -3.8 \\
\hline z13 & 1484.618 & 1484.613 & -3.3 \\
\hline$(x+1) 13$ & 1527.624 & 1527.625 & 0.8 \\
\hline$(y-1) 13$ & 1499.629 & 1499.633 & 2.8 \\
\hline$(y-1) 14$ & 1655.730 & 1655.719 & -6.5 \\
\hline $\mathrm{x} 16$ & 1942.800 & 1942.812 & 6.2 \\
\hline$(x+1) 17$ & 2014.845 & 2014.855 & 4.7 \\
\hline z17 & 1971.839 & 1971.851 & 6.1 \\
\hline$(y-1) 19$ & 2204.956 & 2204.949 & -2.9 \\
\hline $\mathrm{y} 37$ & 4163.990 & 4164.020 & 7.3 \\
\hline$(y-1) 51$ & 5947.765 & 5947.759 & -1.0 \\
\hline$(y-1) 64$ & 7510.742 & 7510.739 & -0.4 \\
\hline z64 & 7495.731 & 7495.745 & 1.8 \\
\hline$(y-1) 65$ & 7638.837 & 7638.843 & 0.8 \\
\hline$(x+1) 65$ & 7666.832 & 7666.809 & -3.0 \\
\hline z65 & 7623.826 & 7623.815 & -1.4 \\
\hline y65 & 7639.845 & 7639.897 & 6.9 \\
\hline x66 & 7752.856 & 7752.908 & 6.6 \\
\hline$(y-1) 67$ & 7888.932 & 7888.916 & -2.0 \\
\hline z67 & 7873.921 & 7873.956 & 4.4 \\
\hline y68 & 8046.041 & 8046.088 & 5.8 \\
\hline z69 & 8117.055 & 8117.018 & -4.5 \\
\hline $\mathrm{x} 70$ & 8246.085 & 8246.084 & -0.1 \\
\hline z70 & 8204.087 & 8204.090 & 0.5 \\
\hline $\mathrm{z} 72$ & 8360.176 & 8360.153 & -2.8 \\
\hline y72 & 8376.195 & 8376.163 & -3.9 \\
\hline $\mathrm{x} 72$ & 8402.174 & 8402.171 & -0.4 \\
\hline y73 & 8523.264 & 8523.224 & -4.6 \\
\hline $\mathrm{x} 74$ & 8648.311 & 8648.329 & 2.0 \\
\hline
\end{tabular}




\begin{tabular}{|c|c|c|c|}
\hline$(\mathrm{x}+1) 74$ & 8649.319 & 8649.358 & 4.5 \\
\hline$(y-1) 75$ & 8784.388 & 8784.398 & 1.2 \\
\hline$(y-1) 76$ & 8885.435 & 8885.486 & 5.7 \\
\hline$(y-1) 77$ & 9000.462 & 9000.477 & 1.7 \\
\hline$(\mathrm{x}+1) 77$ & 9028.457 & 9028.496 & 4.3 \\
\hline y77 & 9001.470 & 9001.512 & 4.7 \\
\hline y78 & 9072.507 & 9072.521 & 1.6 \\
\hline$(\mathrm{x}+1) 78$ & 9099.494 & 9099.533 & 4.2 \\
\hline$(y-1) 79$ & 9185.542 & 9185.594 & 5.6 \\
\hline$(\mathrm{x}+1) 84$ & 9832.834 & 9832.811 & -2.4 \\
\hline$(\mathrm{x}+1) 85$ & 9960.892 & 9960.940 & 4.8 \\
\hline $\mathrm{z} 86$ & 10032.913 & 10032.974 & 6.1 \\
\hline z92 & 10613.174 & 10613.172 & -0.2 \\
\hline z93 & 10750.233 & 10750.253 & 1.9 \\
\hline y93 & 10766.252 & 10766.322 & 6.5 \\
\hline $\mathrm{x} 97$ & 11261.500 & 11261.440 & -5.3 \\
\hline x99 & 11473.652 & 11473.635 & -1.5 \\
\hline y101 & 11675.784 & 11675.751 & -2.8 \\
\hline z101 & 11659.765 & 11659.775 & 0.8 \\
\hline$(x+1) 102$ & 11830.866 & 11830.902 & 3.0 \\
\hline $\mathrm{x} 103$ & 11886.880 & 11886.924 & 3.8 \\
\hline y104 & 11988.995 & 11988.940 & -4.6 \\
\hline$(x+1) 104$ & 12015.982 & 12016.050 & 5.6 \\
\hline z105 & 12088.003 & 12087.962 & -3.4 \\
\hline y105 & 12104.022 & 12104.059 & 3.0 \\
\hline$(x+1) 106$ & 12245.052 & 12245.119 & 5.4 \\
\hline$(x+1) 107$ & 12358.136 & 12358.165 & 2.3 \\
\hline$(y-1) 108$ & 12493.205 & 12493.248 & 3.5 \\
\hline z108 & 12478.194 & 12478.256 & 5.0 \\
\hline $\mathrm{x} 108$ & 12520.192 & 12520.291 & 7.9 \\
\hline $\mathrm{z} 110$ & 12693.321 & 12693.330 & 0.7 \\
\hline$(x+1) 112$ & 12936.443 & 12936.485 & 3.3 \\
\hline $\mathrm{z} 112$ & 12893.437 & 12893.526 & 6.9 \\
\hline $\mathrm{x} 113$ & 13063.530 & 13063.567 & 2.9 \\
\hline$(x+1) 113$ & 13064.538 & 13064.600 & 4.8 \\
\hline
\end{tabular}




\begin{tabular}{|c|c|c|c|}
\hline z113 & 13021.532 & 13021.601 & 5.3 \\
\hline y114 & 13134.603 & 13134.589 & -1.1 \\
\hline z114 & 13118.585 & 13118.581 & -0.3 \\
\hline$(y-1) 115$ & 13296.659 & 13296.667 & 0.6 \\
\hline$(x+1) 115$ & 13324.654 & 13324.686 & 2.4 \\
\hline y117 & 13498.742 & 13498.846 & 7.7 \\
\hline z119 & 13667.839 & 13667.824 & -1.1 \\
\hline y121 & 13911.021 & 13911.098 & 5.5 \\
\hline y122 & 14024.105 & 14024.043 & -4.5 \\
\hline$(x+1) 123$ & 14237.172 & 14237.061 & -7.8 \\
\hline $\mathrm{x} 123$ & 14236.164 & 14236.061 & -7.2 \\
\hline $\mathrm{x} 124$ & 14349.248 & 14349.292 & 3.0 \\
\hline $\mathrm{x} 128$ & 14867.533 & 14867.548 & 1.0 \\
\hline y128 & 14841.554 & 14841.591 & 2.5 \\
\hline$(y-1) 129$ & 14987.615 & 14987.524 & -6.1 \\
\hline $\mathrm{x} 129$ & 15014.602 & 15014.616 & 0.9 \\
\hline y129 & 14988.623 & 14988.638 & 1.0 \\
\hline y132 & 15274.787 & 15274.802 & 1.0 \\
\hline z136 & 15620.938 & 15620.975 & 2.3 \\
\hline $\mathrm{x} 138$ & 15835.975 & 15835.947 & -1.7 \\
\hline z139 & 15865.014 & 15864.989 & -1.6 \\
\hline y140 & 15982.080 & 15982.053 & -1.7 \\
\hline$(y-1) 140$ & 15981.072 & 15981.053 & -1.2 \\
\hline$(y-1) 143$ & 16265.257 & 16265.251 & -0.4 \\
\hline y143 & 16266.265 & 16266.266 & 0.1 \\
\hline $\mathrm{x} 144$ & 16406.287 & 16406.260 & -1.6 \\
\hline$(x+1) 144$ & 16407.295 & 16407.283 & -0.7 \\
\hline y150 & 17116.601 & 17116.594 & -0.4 \\
\hline$(x+1) 159$ & 18180.111 & 18180.101 & -0.5 \\
\hline z160 & 18293.206 & 18293.093 & -6.2 \\
\hline y160 & 18309.225 & 18309.211 & -0.7 \\
\hline$(y-1) 170$ & 19401.710 & 19401.732 & 1.1 \\
\hline$(x+1) 179$ & 20610.245 & 20610.241 & -0.2 \\
\hline y181 & 20737.332 & 20737.329 & -0.1 \\
\hline$(\mathrm{y}-1) 181$ & 20736.324 & 20736.329 & 0.2 \\
\hline
\end{tabular}




\begin{tabular}{|c|c|c|c|}
\hline z193 & 21973.792 & 21973.841 & 2.2 \\
\hline $\mathrm{z} 195$ & 22249.940 & 22250.022 & 3.7 \\
\hline$(\mathrm{x}+1) 195$ & 22292.946 & 22293.080 & 6.1 \\
\hline$(\mathrm{x}+1) 197$ & 22566.057 & 22566.100 & 1.9 \\
\hline $\mathrm{z} 204$ & 23156.348 & 23156.447 & 4.3 \\
\hline$(\mathrm{y}-1) 208$ & 23628.498 & 23628.337 & -6.8 \\
\hline$(\mathrm{x}+1) 222$ & 25132.251 & 25132.256 & 0.2 \\
\hline$(\mathrm{y}-1) 222$ & 25104.256 & 25104.419 & 6.5 \\
\hline$(\mathrm{y}-1) 223$ & 25217.340 & 25217.348 & 0.3 \\
\hline $\mathrm{x} 224$ & 25341.380 & 25341.466 & 3.4 \\
\hline $\mathrm{y} 224$ & 25315.401 & 25315.561 & 6.3 \\
\hline$(\mathrm{y}-1) 224$ & 25314.393 & 25314.593 & 7.9 \\
\hline
\end{tabular}

(2) Light chain of antibody

\begin{tabular}{|c|c|c|c|}
\hline Identified Ion & Theoretical Mass & Observed Mass & Mass Error (ppm) \\
\hline b8 & 896.472 & 896.466 & -6.6 \\
\hline b12 & 1270.652 & 1270.650 & -1.6 \\
\hline b13 & 1341.689 & 1341.690 & 0.9 \\
\hline $\mathrm{c} 13$ & 1358.715 & 1358.728 & 9.8 \\
\hline a14 & 1400.726 & 1400.722 & -2.9 \\
\hline b14 & 1428.721 & 1428.719 & -1.6 \\
\hline$(a+1) 17$ & 1672.851 & 1672.845 & -3.1 \\
\hline a17 & 1671.843 & 1671.841 & -1.1 \\
\hline b17 & 1699.838 & 1699.846 & 5.0 \\
\hline $\mathrm{c} 17$ & 1716.864 & 1716.873 & 5.2 \\
\hline $\mathrm{b} 20$ & 2056.055 & 2056.035 & -9.5 \\
\hline$(a+1) 23$ & 2345.201 & 2345.186 & -6.5 \\
\hline b38 & 4177.085 & 4177.097 & 3.0 \\
\hline $\mathrm{a} 48$ & 5256.782 & 5256.794 & 2.4 \\
\hline$(a+1) 63$ & 6822.553 & 6822.549 & -0.5 \\
\hline c68 & 7181.684 & 7181.663 & -3.0 \\
\hline c69 & 7282.732 & 7282.760 & 3.9 \\
\hline$(a+1) 71$ & 7500.814 & 7500.764 & -6.6 \\
\hline b78 & 8243.212 & 8243.161 & -6.2 \\
\hline$(a+1) 81$ & 8570.379 & 8570.410 & 3.6 \\
\hline b83 & 8859.462 & 8859.437 & -2.8 \\
\hline
\end{tabular}




\begin{tabular}{|c|c|c|c|}
\hline a93 & 10039.924 & 10039.999 & 7.5 \\
\hline c96 & 10489.162 & 10489.194 & 3.1 \\
\hline$(a+1) 96$ & 10445.149 & 10445.251 & 9.8 \\
\hline$(a+1) 97$ & 10502.170 & 10502.228 & 5.5 \\
\hline c98 & 10674.242 & 10674.236 & -0.6 \\
\hline$(a+1) 99$ & 10687.250 & 10687.294 & 4.1 \\
\hline b99 & 10714.237 & 10714.293 & 5.2 \\
\hline a100 & 10787.290 & 10787.286 & -0.4 \\
\hline c102 & 11031.443 & 11031.463 & 1.8 \\
\hline a104 & 11214.533 & 11214.602 & 6.1 \\
\hline b105 & 11370.623 & 11370.622 & -0.1 \\
\hline$(a+1) 109$ & 11742.859 & 11742.793 & -5.6 \\
\hline b109 & 11769.846 & 11769.951 & 8.9 \\
\hline$(a+1) 111$ & 11910.949 & 11910.880 & -5.8 \\
\hline$(a+1) 112$ & 11997.981 & 11998.040 & 5.0 \\
\hline a113 & 12096.042 & 12096.124 & 6.9 \\
\hline b113 & 12124.036 & 12124.133 & 7.9 \\
\hline c114 & 12288.131 & 12288.168 & 3.0 \\
\hline a114 & 12243.110 & 12243.223 & 9.3 \\
\hline c116 & 12548.284 & 12548.255 & -2.3 \\
\hline$(a+1) 117$ & 12601.323 & 12601.332 & 0.7 \\
\hline a118 & 12697.368 & 12697.422 & 4.3 \\
\hline$(a+1) 118$ & 12698.376 & 12698.437 & 4.8 \\
\hline c119 & 12829.421 & 12829.425 & 0.3 \\
\hline a119 & 12784.400 & 12784.410 & 0.8 \\
\hline $\mathrm{c} 121$ & 13073.491 & 13073.387 & -7.9 \\
\hline b121 & 13056.464 & 13056.437 & -2.1 \\
\hline b122 & 13184.523 & 13184.537 & 1.1 \\
\hline $\mathrm{c} 122$ & 13201.549 & 13201.668 & 9.0 \\
\hline$(a+1) 126$ & 13542.768 & 13542.759 & -0.7 \\
\hline b129 & 13828.872 & 13828.886 & 1.0 \\
\hline a132 & 14101.016 & 14101.036 & 1.5 \\
\hline$(a+1) 132$ & 14102.023 & 14102.118 & 6.7 \\
\hline b133 & 14242.095 & 14241.974 & -8.5 \\
\hline b142 & 15346.630 & 15346.709 & 5.2 \\
\hline
\end{tabular}




\begin{tabular}{|c|c|c|c|}
\hline c152 & 16545.312 & 16545.256 & -3.4 \\
\hline c158 & 17146.557 & 17146.598 & 2.4 \\
\hline a173 & 18771.268 & 18771.425 & 8.4 \\
\hline b179 & 19401.590 & 19401.732 & 7.3 \\
\hline$(a+1) 180$ & 19461.635 & 19461.479 & -8.0 \\
\hline c184 & 19982.871 & 19982.703 & -8.4 \\
\hline c187 & 20377.068 & 20376.921 & -7.2 \\
\hline b187 & 20360.041 & 20360.190 & 7.3 \\
\hline b188 & 20488.136 & 20488.077 & -2.9 \\
\hline c189 & 20604.231 & 20604.174 & -2.8 \\
\hline b190 & 20750.268 & 20750.469 & 9.7 \\
\hline$(a+1) 192$ & 20896.319 & 20896.521 & 9.6 \\
\hline a193 & 21024.354 & 21024.261 & -4.5 \\
\hline b194 & 21151.417 & 21151.496 & 3.7 \\
\hline b197 & 21517.583 & 21517.517 & -3.1 \\
\hline c198 & 21591.630 & 21591.748 & 5.5 \\
\hline$(a+1) 198$ & 21547.617 & 21547.823 & 9.6 \\
\hline c199 & 21704.714 & 21704.910 & 9.0 \\
\hline$(a+1) 200$ & 21747.733 & 21747.873 & 6.4 \\
\hline a202 & 21930.810 & 21930.718 & -4.2 \\
\hline b203 & 22057.873 & 22057.926 & 2.4 \\
\hline a205 & 22259.021 & 22259.089 & 3.0 \\
\hline b207 & 22521.116 & 22521.134 & 0.8 \\
\hline c209 & 22808.287 & 22808.243 & -1.9 \\
\hline $\mathrm{c} 211$ & 22994.351 & 22994.510 & 6.9 \\
\hline $\mathrm{x} 17$ & 1870.851 & 1870.852 & 1.0 \\
\hline$(x+1) 18$ & 1972.906 & 1972.903 & -1.4 \\
\hline $\mathrm{y} 51$ & 5652.662 & 5652.715 & 9.4 \\
\hline$(x+1) 57$ & 6323.926 & 6323.879 & -7.4 \\
\hline$(y-1) 62$ & 6752.164 & 6752.122 & -6.3 \\
\hline$(x+1) 63$ & 6894.202 & 6894.147 & -8.0 \\
\hline $\mathrm{z} 67$ & 7379.466 & 7379.493 & 3.6 \\
\hline $\mathrm{x} 70$ & 7776.686 & 7776.741 & 7.1 \\
\hline$(x+1) 82$ & 9196.383 & 9196.367 & -1.7 \\
\hline z90 & 9896.795 & 9896.826 & 3.1 \\
\hline
\end{tabular}




\begin{tabular}{|c|c|c|c|}
\hline$(x+1) 96$ & 10593.066 & 10593.133 & 6.3 \\
\hline y97 & 10713.148 & 10713.251 & 9.7 \\
\hline z98 & 10810.213 & 10810.255 & 3.9 \\
\hline$(\mathrm{y}-1) 98$ & 10825.224 & 10825.300 & 7.0 \\
\hline$(y-1) 101$ & 11158.393 & 11158.448 & 4.9 \\
\hline$(y-1) 104$ & 11397.520 & 11397.543 & 2.1 \\
\hline$(x+1) 105$ & 11496.552 & 11496.467 & -7.4 \\
\hline $\mathrm{x} 107$ & 11752.693 & 11752.783 & 7.7 \\
\hline$(y-1) 112$ & 12281.044 & 12281.062 & 1.5 \\
\hline z116 & 12609.182 & 12609.242 & 4.8 \\
\hline$(x+1) 117$ & 12799.256 & 12799.348 & 7.2 \\
\hline$(x+1) 119$ & 13056.405 & 13056.437 & 2.5 \\
\hline$(x+1) 120$ & 13143.437 & 13143.516 & 6.0 \\
\hline $\mathrm{z} 128$ & 14150.819 & 14150.958 & 9.8 \\
\hline $\mathrm{x} 131$ & 14525.949 & 14525.958 & 0.6 \\
\hline$(x+1) 134$ & 14881.111 & 14881.175 & 4.3 \\
\hline $\mathrm{x} 140$ & 15494.467 & 15494.492 & 1.6 \\
\hline$(x+1) 141$ & 15596.523 & 15596.422 & -6.5 \\
\hline x142 & 15742.583 & 15742.507 & -4.9 \\
\hline z143 & 15815.612 & 15815.543 & -4.4 \\
\hline$(y-1) 151$ & 16480.889 & 16480.987 & 6.0 \\
\hline y152 & 16637.998 & 16638.073 & 4.5 \\
\hline $\mathrm{x} 154$ & 16848.062 & 16848.033 & -1.7 \\
\hline y162 & 17578.460 & 17578.626 & 9.4 \\
\hline z165 & 17909.625 & 17909.649 & 1.3 \\
\hline$(x+1) 176$ & 19203.356 & 19203.484 & 6.7 \\
\hline$(y-1) 178$ & 19524.504 & 19524.575 & 3.6 \\
\hline$(x+1) 180$ & 19779.626 & 19779.797 & 8.7 \\
\hline$(y-1) 181$ & 19838.663 & 19838.694 & 1.6 \\
\hline$(x+1) 184$ & 20222.875 & 20222.713 & -8.0 \\
\hline y186 & 20410.978 & 20410.833 & -7.1 \\
\hline $\mathrm{x} 186$ & 20436.958 & 20436.913 & -2.2 \\
\hline z186 & 20394.960 & 20395.067 & 5.3 \\
\hline y189 & 20725.149 & 20725.011 & -6.6 \\
\hline$(y-1) 189$ & 20724.141 & 20724.072 & -3.3 \\
\hline
\end{tabular}




\begin{tabular}{|c|c|c|c|}
\hline $\mathrm{x} 191$ & 20954.177 & 20954.380 & 9.7 \\
\hline $\mathrm{x} 194$ & 21267.377 & 21267.512 & 6.3 \\
\hline $\mathrm{y} 197$ & 21569.547 & 21569.591 & 2.0 \\
\hline $\mathrm{y} 198$ & 21668.616 & 21668.730 & 5.3 \\
\hline$(\mathrm{x}+1) 198$ & 21695.603 & 21695.776 & 8.0 \\
\hline$(\mathrm{x}+1) 204$ & 22227.852 & 22228.041 & 8.5 \\
\hline $\mathrm{x} 205$ & 22323.897 & 22323.688 & -9.4 \\
\hline $\mathrm{z} 207$ & 22496.990 & 22497.065 & 3.4 \\
\hline $\mathrm{y} 207$ & 22513.008 & 22513.183 & 7.7 \\
\hline $\mathrm{y} 208$ & 22614.056 & 22614.225 & 7.5 \\
\hline$(\mathrm{y}-1) 210$ & 22868.218 & 22868.413 & 8.5 \\
\hline $\mathrm{y} 211$ & 22982.310 & 22982.220 & -3.9 \\
\hline $\mathrm{z} 211$ & 22966.291 & 22966.452 & 7.0 \\
\hline
\end{tabular}

(3) Heavy chain of antibody

\begin{tabular}{|c|c|c|c|}
\hline Identified Ion & Theoretical Mass & Observed Mass & Mass Error (ppm) \\
\hline$(a+1) 16$ & 1649.886 & 1649.882 & -2.4 \\
\hline a16 & 1648.878 & 1648.884 & 3.4 \\
\hline b16 & 1676.873 & 1676.880 & 3.9 \\
\hline$(a+1) 63$ & 6809.423 & 6809.405 & -2.5 \\
\hline $\mathrm{a} 65$ & 7008.531 & 7008.522 & -1.3 \\
\hline$(a+1) 68$ & 7336.704 & 7336.689 & -2.0 \\
\hline $\mathrm{c} 73$ & 7894.034 & 7894.018 & -2.1 \\
\hline$(a+1) 80$ & 8640.382 & 8640.362 & -2.2 \\
\hline $\mathrm{a} 83$ & 8968.532 & 8968.536 & 0.4 \\
\hline b98 & 10511.211 & 10511.192 & -1.8 \\
\hline$(a+1) 99$ & 10640.325 & 10640.297 & -2.6 \\
\hline b99 & 10667.312 & 10667.320 & 0.7 \\
\hline $\mathrm{c} 101$ & 10946.434 & 10946.399 & -3.2 \\
\hline a102 & 11048.481 & 11048.515 & 3.1 \\
\hline$(a+1) 110$ & 11946.970 & 11946.997 & 2.3 \\
\hline $\mathrm{c} 110$ & 11990.983 & 11991.017 & 2.9 \\
\hline b111 & 12088.000 & 12087.962 & -3.1 \\
\hline a111 & 12060.005 & 12060.047 & 3.5 \\
\hline a113 & 12278.110 & 12278.129 & 1.5 \\
\hline$(a+1) 115$ & 12507.229 & 12507.263 & 2.7 \\
\hline
\end{tabular}




\begin{tabular}{|c|c|c|c|}
\hline$(a+1) 116$ & 12693.308 & 12693.330 & 1.7 \\
\hline b135 & 14542.188 & 14542.185 & -0.2 \\
\hline$(a+1) 148$ & 15685.789 & 15685.828 & 2.5 \\
\hline$(a+1) 163$ & 17287.593 & 17287.608 & 0.9 \\
\hline b188 & 19837.892 & 19837.947 & 2.8 \\
\hline a193 & 20347.141 & 20347.124 & -0.8 \\
\hline a197 & 20745.394 & 20745.428 & 1.7 \\
\hline c199 & 20974.500 & 20974.528 & 1.4 \\
\hline$(a+1) 202$ & 21217.635 & 21217.593 & -1.9 \\
\hline a203 & 21273.648 & 21273.730 & 3.9 \\
\hline a204 & 21374.696 & 21374.764 & 3.2 \\
\hline c205 & 21547.776 & 21547.823 & 2.2 \\
\hline c206 & 21648.823 & 21648.825 & 0.1 \\
\hline$(a+1) 207$ & 21767.873 & 21767.892 & 0.8 \\
\hline a207 & 21766.865 & 21766.884 & 0.9 \\
\hline a209 & 21981.951 & 21981.888 & -2.8 \\
\hline a210 & 22095.994 & 22095.909 & -3.8 \\
\hline b210 & 22123.989 & 22123.959 & -1.4 \\
\hline b211 & 22223.057 & 22223.065 & 0.3 \\
\hline b214 & 22602.254 & 22602.185 & -3.0 \\
\hline b215 & 22699.307 & 22699.314 & 0.3 \\
\hline a216 & 22758.344 & 22758.286 & -2.5 \\
\hline b217 & 22900.382 & 22900.357 & -1.1 \\
\hline c222 & 23489.689 & 23489.679 & -0.4 \\
\hline b223 & 23600.757 & 23600.764 & 0.3 \\
\hline$(a+1) 225$ & 23801.881 & 23801.942 & 2.5 \\
\hline$(a+1) 229$ & 24216.062 & 24216.014 & -2.0 \\
\hline b237 & 25121.432 & 25121.435 & 0.1 \\
\hline$(a+1) 238$ & 25196.447 & 25196.488 & 1.7 \\
\hline$(a+1) 239$ & 25293.499 & 25293.460 & -1.6 \\
\hline a239 & 25292.492 & 25292.511 & 0.8 \\
\hline b239 & 25320.486 & 25320.561 & 3.0 \\
\hline$(a+1) 240$ & 25364.537 & 25364.574 & 1.5 \\
\hline a240 & 25363.529 & 25363.571 & 1.7 \\
\hline c240 & 25408.550 & 25408.626 & 3.0 \\
\hline
\end{tabular}




\begin{tabular}{|c|c|c|c|}
\hline$(a+1) 241$ & 25461.589 & 25461.551 & -1.5 \\
\hline c241 & 25505.603 & 25505.553 & -2.0 \\
\hline a241 & 25460.581 & 25460.570 & -0.5 \\
\hline c245 & 25917.835 & 25917.938 & 4.0 \\
\hline$(a+1) 252$ & 26621.217 & 26621.191 & -1.0 \\
\hline b252 & 26648.204 & 26648.188 & -0.6 \\
\hline b253 & 26745.257 & 26745.184 & -2.7 \\
\hline$(a+1) 254$ & 26815.323 & 26815.283 & -1.5 \\
\hline a254 & 26814.315 & 26814.349 & 1.3 \\
\hline c256 & 27084.484 & 27084.501 & 0.6 \\
\hline a259 & 27383.632 & 27383.608 & -0.9 \\
\hline b266 & 28210.069 & 28210.039 & -1.1 \\
\hline b282 & 29945.854 & 29945.817 & -1.2 \\
\hline c289 & 30915.325 & 30915.328 & 0.1 \\
\hline b289 & 30898.298 & 30898.395 & 3.1 \\
\hline c291 & 31071.414 & 31071.357 & -1.8 \\
\hline a301 & 32187.035 & 32186.949 & -2.7 \\
\hline c311 & 33501.618 & 33501.550 & -2.1 \\
\hline$(a+1) 312$ & 33556.673 & 33556.618 & -1.6 \\
\hline$(a+1) 315$ & 33855.858 & 33855.859 & 0.0 \\
\hline$(a+1) 316$ & 33956.906 & 33957.004 & 2.9 \\
\hline c324 & 35006.422 & 35006.336 & -2.5 \\
\hline b325 & 35046.417 & 35046.291 & -3.6 \\
\hline$(a+1) 325$ & 35019.430 & 35019.491 & 1.7 \\
\hline$(a+1) 326$ & 35147.525 & 35147.406 & -3.4 \\
\hline b327 & 35303.555 & 35303.494 & -1.7 \\
\hline a329 & 35566.718 & 35566.850 & 3.7 \\
\hline b334 & 36124.953 & 36124.987 & 0.9 \\
\hline b337 & 36437.169 & 36437.294 & 3.4 \\
\hline c340 & 36719.338 & 36719.330 & -0.2 \\
\hline a356 & 38465.317 & 38465.390 & 1.9 \\
\hline a376 & 40709.450 & 40709.346 & -2.6 \\
\hline a380 & 41106.719 & 41106.558 & -3.9 \\
\hline c386 & 41874.068 & 41874.016 & -1.2 \\
\hline a386 & 41829.047 & 41829.047 & 0.0 \\
\hline
\end{tabular}




\begin{tabular}{|c|c|c|c|}
\hline b387 & 41928.079 & 41927.928 & -3.6 \\
\hline a387 & 41900.084 & 41900.104 & 0.5 \\
\hline b404 & 43901.954 & 43901.820 & -3.1 \\
\hline$(a+1) 405$ & 43972.020 & 43971.890 & -3.0 \\
\hline$(a+1) 413$ & 44792.380 & 44792.322 & -1.3 \\
\hline$(a+1) 422$ & 45900.013 & 45899.892 & -2.6 \\
\hline $\mathrm{c} 433$ & 47235.591 & 47235.415 & -3.7 \\
\hline a435 & 47376.670 & 47376.649 & -0.4 \\
\hline$(a+1) 437$ & 47645.777 & 47645.603 & -3.7 \\
\hline $\mathrm{c} 450$ & 49198.528 & 49198.382 & -3.0 \\
\hline $\mathrm{a} 451$ & 49266.591 & 49266.508 & -1.7 \\
\hline$(x+1) 12$ & 1334.696 & 1334.696 & 0.1 \\
\hline$(x+1) 14$ & 1585.797 & 1585.791 & -3.8 \\
\hline $\mathrm{x} 16$ & 1834.933 & 1834.926 & -3.8 \\
\hline y16 & 1808.953 & 1808.951 & -1.1 \\
\hline$(x+1) 19$ & 2173.079 & 2173.081 & 1.1 \\
\hline y20 & 2277.132 & 2277.136 & 1.5 \\
\hline $\mathrm{y} 21$ & 2376.201 & 2376.199 & -1.0 \\
\hline$y 22$ & 2463.233 & 2463.237 & 1.7 \\
\hline$(x+1) 46$ & 5295.566 & 5295.556 & -1.9 \\
\hline $\mathrm{x} 71$ & 8078.846 & 8078.873 & 3.4 \\
\hline $\mathrm{z} 73$ & 8220.933 & 8220.914 & -2.2 \\
\hline y77 & 8732.200 & 8732.209 & 1.1 \\
\hline$(y-1) 87$ & 9815.774 & 9815.785 & 1.1 \\
\hline$(x+1) 88$ & 9944.817 & 9944.794 & -2.3 \\
\hline x91 & 10300.963 & 10300.938 & -2.4 \\
\hline z94 & 10599.150 & 10599.191 & 3.8 \\
\hline z96 & 10809.287 & 10809.280 & -0.7 \\
\hline y96 & 10825.306 & 10825.300 & -0.5 \\
\hline$(y-1) 97$ & 10925.346 & 10925.351 & 0.4 \\
\hline z101 & 11397.578 & 11397.543 & -3.0 \\
\hline$(y-1) 102$ & 11541.631 & 11541.617 & -1.3 \\
\hline z103 & 11682.722 & 11682.762 & 3.5 \\
\hline $\mathrm{z} 111$ & 12492.198 & 12492.224 & 2.1 \\
\hline y112 & 12609.264 & 12609.242 & -1.7 \\
\hline
\end{tabular}




\begin{tabular}{|c|c|c|c|}
\hline y115 & 12979.486 & 12979.528 & 3.3 \\
\hline z116 & 13060.520 & 13060.562 & 3.2 \\
\hline $\mathrm{z} 117$ & 13131.557 & 13131.591 & 2.6 \\
\hline y118 & 13244.628 & 13244.650 & 1.6 \\
\hline y121 & 13556.844 & 13556.895 & 3.7 \\
\hline $\mathrm{x} 123$ & 13783.899 & 13783.913 & 1.0 \\
\hline$(x+1) 125$ & 14012.070 & 14012.104 & 2.4 \\
\hline z128 & 14362.224 & 14362.247 & 1.6 \\
\hline $\mathrm{x} 133$ & 14945.508 & 14945.547 & 2.6 \\
\hline$(y-1) 151$ & 17079.616 & 17079.673 & 3.3 \\
\hline$(y-1) 154$ & 17465.760 & 17465.797 & 2.1 \\
\hline x166 & 18809.478 & 18809.468 & -0.5 \\
\hline $\mathrm{x} 180$ & 20555.247 & 20555.260 & 0.6 \\
\hline$(y-1) 181$ & 20627.328 & 20627.283 & -2.2 \\
\hline z181 & 20612.317 & 20612.324 & 0.3 \\
\hline$(x+1) 181$ & 20655.323 & 20655.344 & 1.0 \\
\hline$(x+1) 183$ & 20869.418 & 20869.443 & 1.2 \\
\hline$(y-1) 185$ & 21039.560 & 21039.485 & -3.6 \\
\hline y185 & 21040.568 & 21040.536 & -1.5 \\
\hline z187 & 21227.598 & 21227.588 & -0.5 \\
\hline$(x+1) 189$ & 21498.715 & 21498.775 & 2.8 \\
\hline $\mathrm{x} 191$ & 21695.808 & 21695.776 & -1.5 \\
\hline $\mathrm{x} 193$ & 21938.941 & 21938.944 & 0.1 \\
\hline z193 & 21896.943 & 21897.005 & 2.8 \\
\hline $\mathrm{x} 195$ & 22183.066 & 22183.082 & 0.7 \\
\hline$(x+1) 195$ & 22184.073 & 22184.146 & 3.3 \\
\hline y196 & 22270.170 & 22270.126 & -2.0 \\
\hline $\mathrm{x} 196$ & 22296.150 & 22296.159 & 0.4 \\
\hline$(y-1) 197$ & 22370.210 & 22370.196 & -0.6 \\
\hline z197 & 22355.199 & 22355.266 & 3.0 \\
\hline$(x+1) 198$ & 22513.232 & 22513.183 & -2.2 \\
\hline$(y-1) 198$ & 22485.237 & 22485.284 & 2.1 \\
\hline y199 & 22614.340 & 22614.278 & -2.7 \\
\hline$(y-1) 199$ & 22613.332 & 22613.306 & -1.2 \\
\hline y200 & 22711.393 & 22711.369 & -1.0 \\
\hline
\end{tabular}




\begin{tabular}{|c|c|c|c|}
\hline $\mathrm{z} 201$ & 22823.469 & 22823.549 & 3.5 \\
\hline z202 & 22920.522 & 22920.529 & 0.3 \\
\hline $\mathrm{x} 202$ & 22962.520 & 22962.565 & 2.0 \\
\hline$(y-1) 203$ & 23032.585 & 23032.588 & 0.1 \\
\hline$(x+1) 203$ & 23060.580 & 23060.581 & 0.0 \\
\hline$(y-1) 205$ & 23292.738 & 23292.742 & 0.2 \\
\hline $\mathrm{x} 207$ & 23565.862 & 23565.819 & -1.8 \\
\hline y208 & 23626.915 & 23626.940 & 1.1 \\
\hline x209 & 23749.947 & 23750.030 & 3.5 \\
\hline$(x+1) 209$ & 23750.954 & 23751.044 & 3.8 \\
\hline $\mathrm{x} 210$ & 23806.968 & 23807.013 & 1.9 \\
\hline $\mathrm{y} 211$ & 23838.010 & 23837.995 & -0.6 \\
\hline $\mathrm{y} 215$ & 24290.274 & 24290.210 & -2.6 \\
\hline y216 & 24361.311 & 24361.232 & -3.3 \\
\hline $\mathrm{z} 216$ & 24345.292 & 24345.237 & -2.3 \\
\hline $\mathrm{x} 217$ & 24484.343 & 24484.253 & -3.7 \\
\hline $\mathrm{x} 224$ & 25221.605 & 25221.507 & -3.9 \\
\hline z224 & 25179.607 & 25179.510 & -3.9 \\
\hline$(y-1) 224$ & 25194.618 & 25194.566 & -2.1 \\
\hline $\mathrm{y} 225$ & 25323.721 & 25323.650 & -2.8 \\
\hline $\mathrm{z} 225$ & 25307.702 & 25307.711 & 0.3 \\
\hline y226 & 25438.748 & 25438.726 & -0.9 \\
\hline z236 & 26535.307 & 26535.277 & -1.1 \\
\hline$(x+1) 237$ & 26707.355 & 26707.298 & -2.1 \\
\hline $\mathrm{z} 240$ & 26966.472 & 26966.398 & -2.7 \\
\hline$(y-1) 240$ & 26981.483 & 26981.429 & -2.0 \\
\hline$(x+1) 242$ & 27234.625 & 27234.552 & -2.7 \\
\hline$(x+1) 248$ & 27913.924 & 27914.035 & 4.0 \\
\hline y250 & 28151.048 & 28151.160 & 4.0 \\
\hline $\mathrm{x} 251$ & 28305.086 & 28305.075 & -0.4 \\
\hline$(x+1) 255$ & 28664.279 & 28664.248 & -1.1 \\
\hline $\mathrm{z} 256$ & 28708.305 & 28708.212 & -3.2 \\
\hline$(x+1) 256$ & 28751.311 & 28751.408 & 3.4 \\
\hline$(y-1) 258$ & 28907.401 & 28907.349 & -1.8 \\
\hline y269 & 30014.010 & 30014.066 & 1.8 \\
\hline
\end{tabular}




\begin{tabular}{|c|c|c|c|}
\hline $\mathrm{x} 271$ & 30214.054 & 30213.934 & -4.0 \\
\hline$(x+1) 289$ & 32081.004 & 32080.882 & -3.8 \\
\hline$(y-1) 298$ & 33098.558 & 33098.564 & 0.2 \\
\hline z298 & 33083.547 & 33083.583 & 1.1 \\
\hline x300 & 33368.667 & 33368.788 & 3.6 \\
\hline$(y-1) 305$ & 33825.939 & 33826.059 & 3.5 \\
\hline z306 & 33881.965 & 33881.918 & -1.4 \\
\hline$(x+1) 307$ & 33996.008 & 33996.044 & 1.1 \\
\hline y308 & 34070.068 & 34069.971 & -2.8 \\
\hline$(y-1) 313$ & 34458.215 & 34458.128 & -2.5 \\
\hline x317 & 34884.414 & 34884.392 & -0.6 \\
\hline$(y-1) 320$ & 35138.601 & 35138.565 & -1.0 \\
\hline$(y-1) 322$ & 35384.738 & 35384.855 & 3.3 \\
\hline$(y-1) 326$ & 35753.939 & 35753.870 & -1.9 \\
\hline z328 & 35927.008 & 35926.954 & -1.5 \\
\hline z329 & 35998.045 & 35998.041 & -0.1 \\
\hline y336 & 36719.400 & 36719.330 & -1.9 \\
\hline x343 & 37548.740 & 37548.624 & -3.1 \\
\hline y343 & 37522.761 & 37522.757 & -0.1 \\
\hline x349 & 38147.995 & 38148.145 & 3.9 \\
\hline $\mathrm{z} 352$ & 38460.260 & 38460.224 & -0.9 \\
\hline x355 & 38925.438 & 38925.298 & -3.6 \\
\hline$(x+1) 359$ & 39370.612 & 39370.567 & -1.1 \\
\hline x366 & 40152.948 & 40153.059 & 2.8 \\
\hline$(y-1) 368$ & 40298.046 & 40298.094 & 1.2 \\
\hline$(y-1) 371$ & 40571.178 & 40571.138 & -1.0 \\
\hline y372 & 40685.270 & 40685.220 & -1.2 \\
\hline$(x+1) 372$ & 40712.257 & 40712.276 & 0.5 \\
\hline y373 & 40814.313 & 40814.179 & -3.3 \\
\hline$(x+1) 373$ & 40841.300 & 40841.172 & -3.1 \\
\hline x382 & 41830.769 & 41830.604 & -3.9 \\
\hline$(y-1) 382$ & 41803.782 & 41803.808 & 0.6 \\
\hline$(x+1) 383$ & 41944.861 & 41944.695 & -4.0 \\
\hline$(x+1) 385$ & 42144.977 & 42144.980 & 0.1 \\
\hline y385 & 42117.990 & 42118.144 & 3.7 \\
\hline
\end{tabular}




\begin{tabular}{|c|c|c|c|}
\hline$(\mathrm{y}-1) 394$ & 43055.475 & 43055.319 & -3.6 \\
\hline $\mathrm{z} 405$ & 44261.036 & 44260.881 & -3.5 \\
\hline $\mathrm{y} 408$ & 44705.260 & 44705.360 & 2.2 \\
\hline $\mathrm{x} 409$ & 44844.324 & 44844.375 & 1.2 \\
\hline$(\mathrm{x}+1) 410$ & 44902.353 & 44902.469 & 2.6 \\
\hline $\mathrm{y} 419$ & 45940.974 & 45940.921 & -1.2 \\
\hline $\mathrm{y} 432$ & 47314.611 & 47314.511 & -2.1 \\
\hline$(\mathrm{x}+1) 435$ & 47631.679 & 47631.849 & 3.6 \\
\hline $\mathrm{y} 438$ & 47917.892 & 47917.826 & -1.4 \\
\hline $\mathrm{x} 440$ & 48159.946 & 48159.810 & -2.8 \\
\hline$(\mathrm{y}-1) 448$ & 48868.387 & 48868.274 & -2.3 \\
\hline$(\mathrm{y}-1) 453$ & 49453.662 & 49453.548 & -2.3 \\
\hline
\end{tabular}

